Journal of Sustainable Agricultural Sciences
http://jsas.journals.ekb.eg/

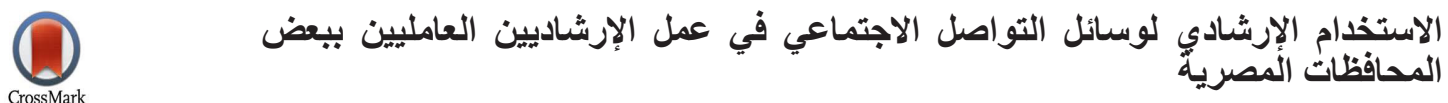

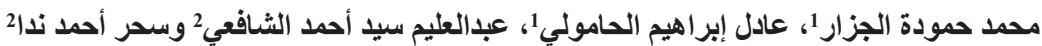

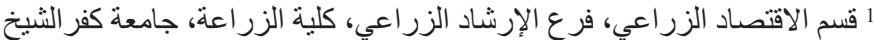

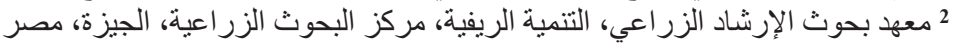

استهاف هذا البحث التعرف على استخدام العاملين الإرشاديين لوسائل التو اصل الاجتماعي في العمل الإرشادي

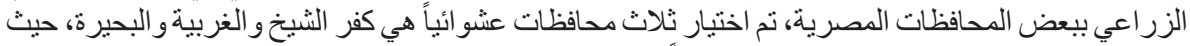

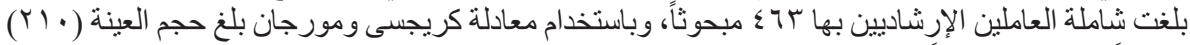

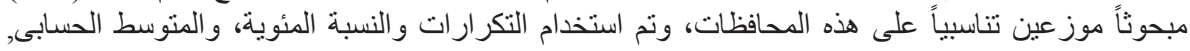

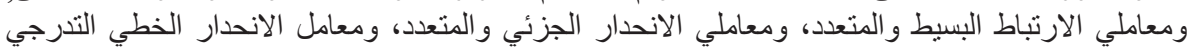

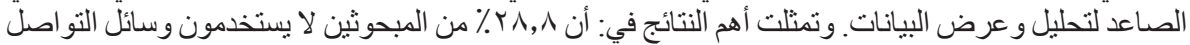

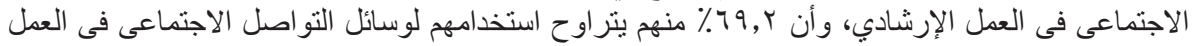

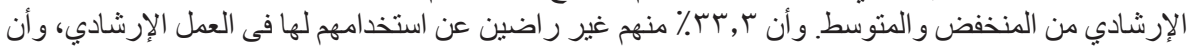

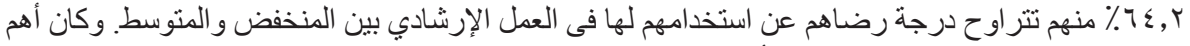

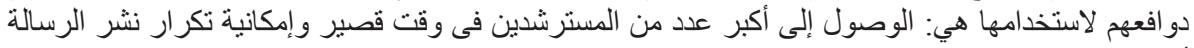

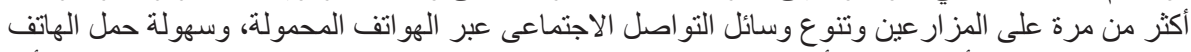

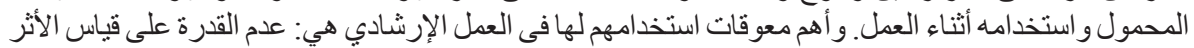

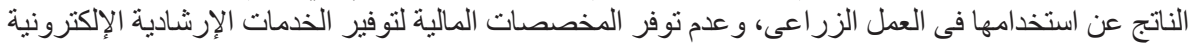

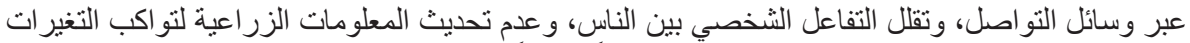

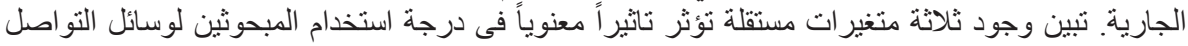

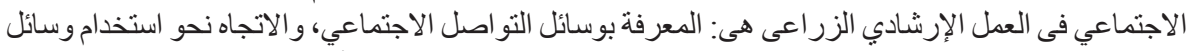

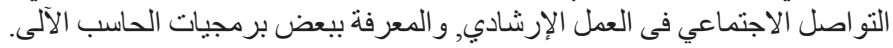

الكلمات المفتاحية: الإرشاد، العاملين، وسائل التواصل الاجتماعي، الفيسبوك، الو اتساب، اليوتيوب، التويتر.

المقدمة ومشكلة البحث

وتزايد المخاوف تجاه توفير الغذاء وتحقيق الامن الغذائي، الذي الذي التياء

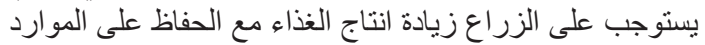

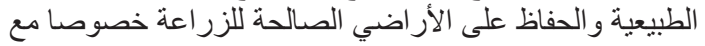

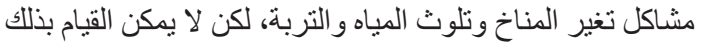

فى ظل اساليب الزر اعة التقليدية التي لا تمكنهم من فعل ذللك.

ويتم تنمية قطاع الزراعة من خلال محورين أساسين هما:

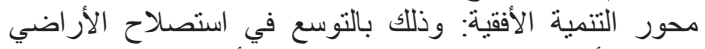

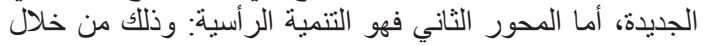

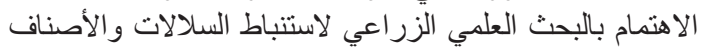

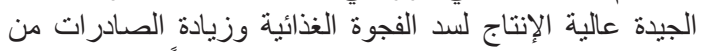

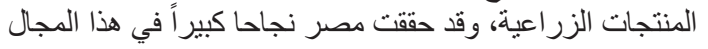

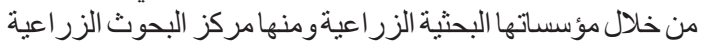
بمعاهده المختلفة، وكليات الزر اعة واعلئه المركز القومي للبحوث.

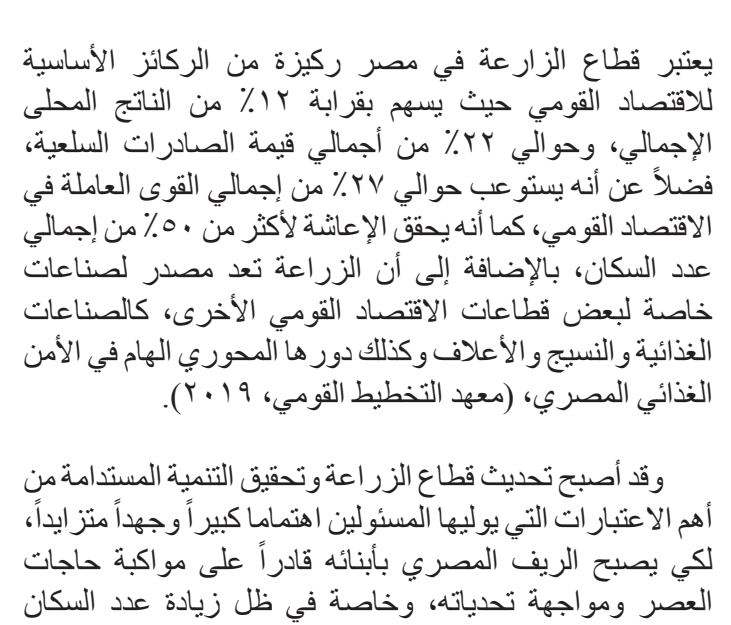




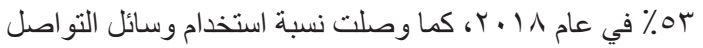

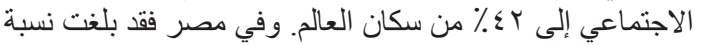

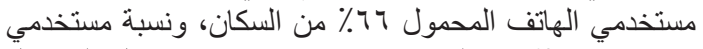

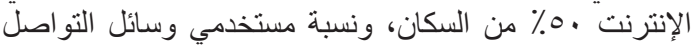

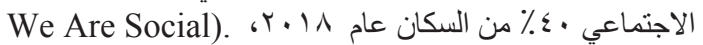

(LTD, .2018

و استحوذت وسائل التو اصل الاجتماعي على مساحة كبيرة

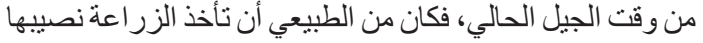

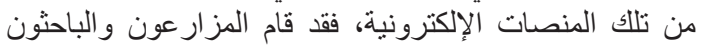

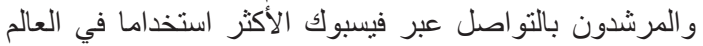

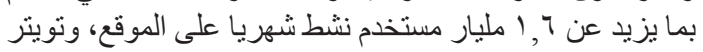

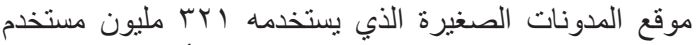

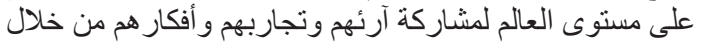

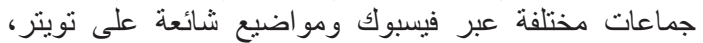

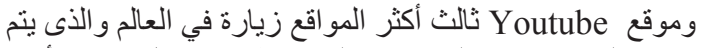

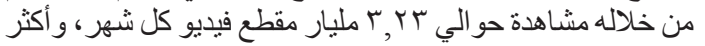

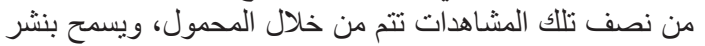

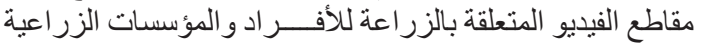

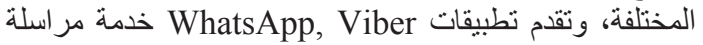

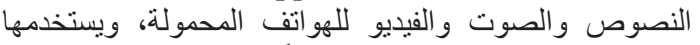

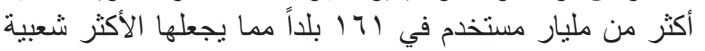

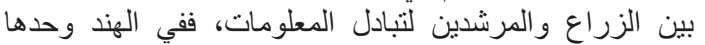

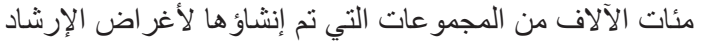
الزر اعي والخدمات الاستشارية الزر اعية، ( Bhattacharjee .(and Saravanan, 2017

ويمكن للإرشاد الزراعي الاستفادة من وسائل التواصل

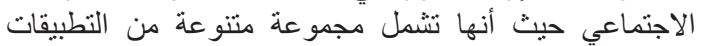

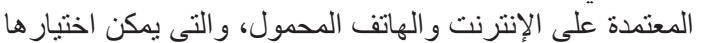

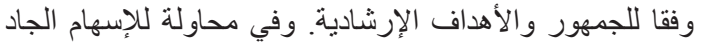

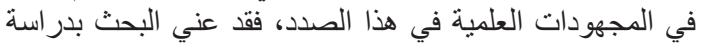

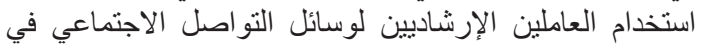
العمل الإرشادي ببعض الإزمادين لمحافظات المصرية.

ويو اجه الإرشاد الزر اعي العديد من الانتقادات نظر اً لقصور

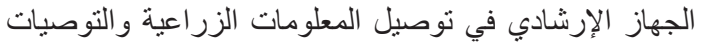

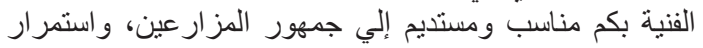

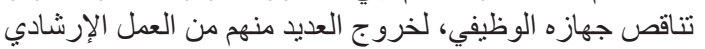

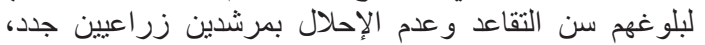

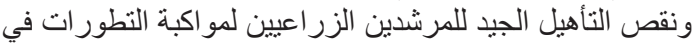

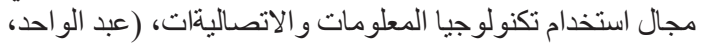

( $T \cdot 10$

ونظرا لما يعانيه كل من الباحثين والعاملين الإرشاديين

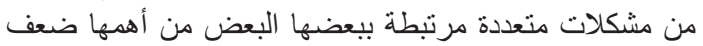

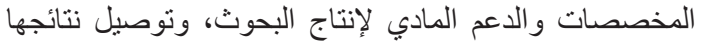

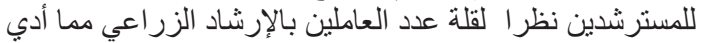

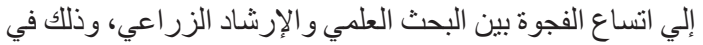

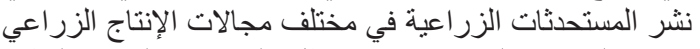

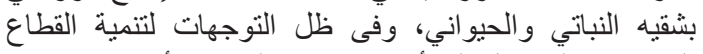

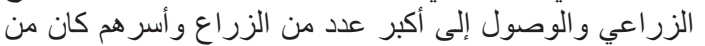

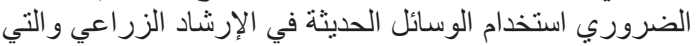
من بينها وسائل التو اصل الاجتماعي، لذا أجري هذا الإند البحث للإجابة
ويعد جهاز الإرشاد الزراعي أحد النظم التعليمية العاملة

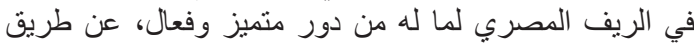

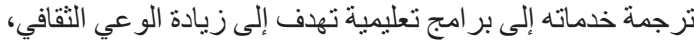

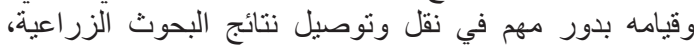

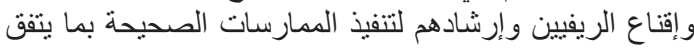

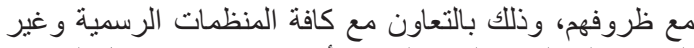

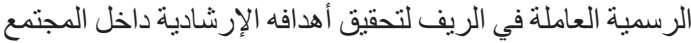

$$
\text { الريفي، (عبد الواحد، } 0 \text { الرية أر أ). }
$$

ويستخدم الإرشاد الزراعي في ذللك العديد من الطرق

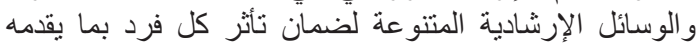

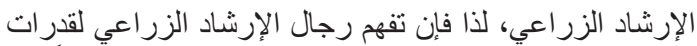

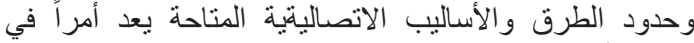

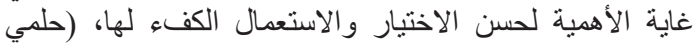

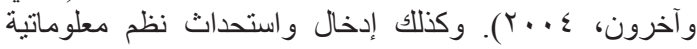

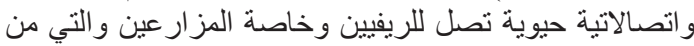

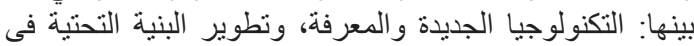

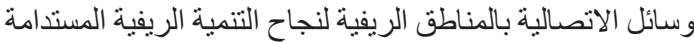

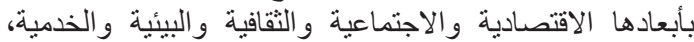

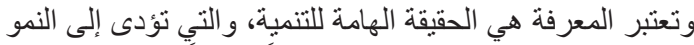

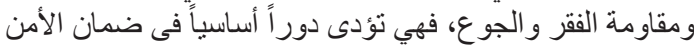

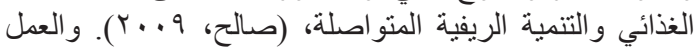

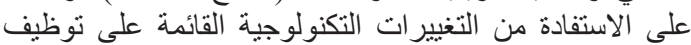

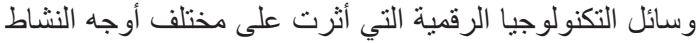

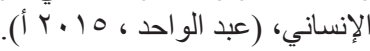

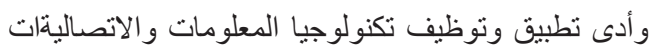

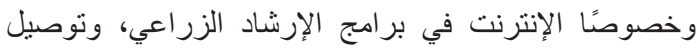

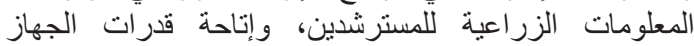

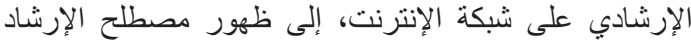

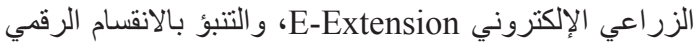

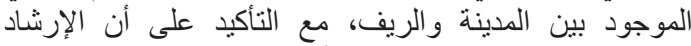

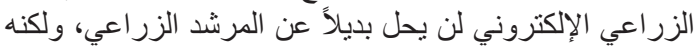

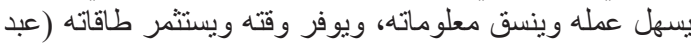

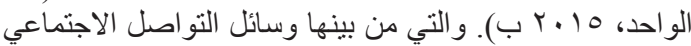

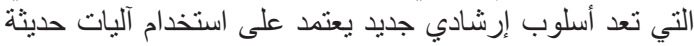

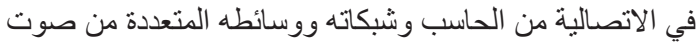

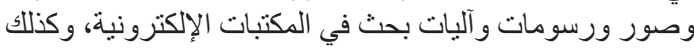

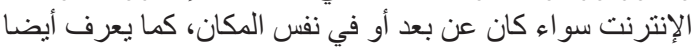

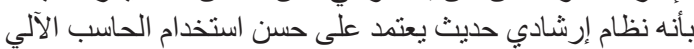

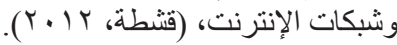

وبات استخدام وسائل التواصل الاجتماعي فى العمل فئل

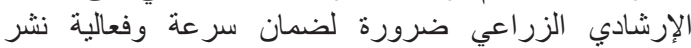

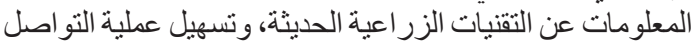

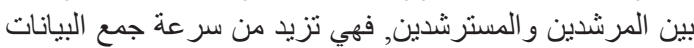

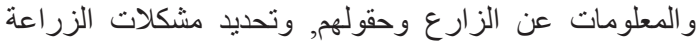

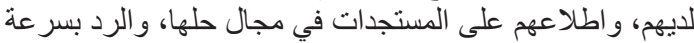

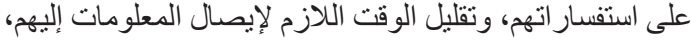

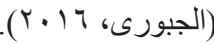

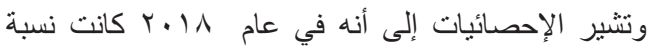

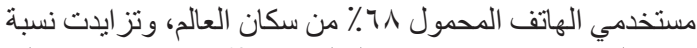

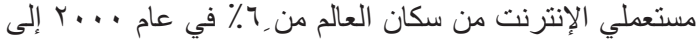

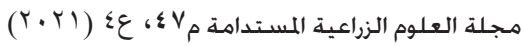


مع التأكيد علي أن أغلب الاتصاليةات بين المعلمين و المتعلمين

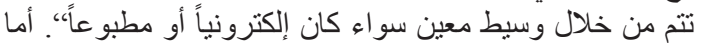

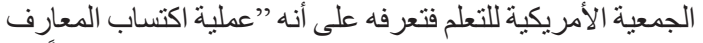

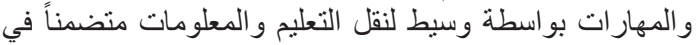

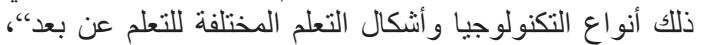

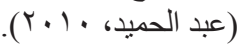

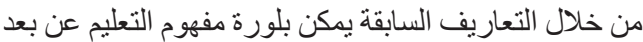

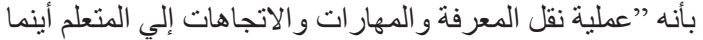

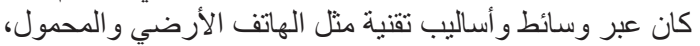

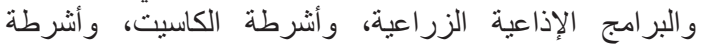

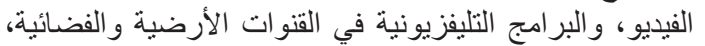

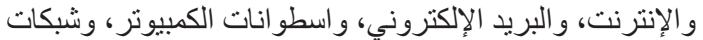

الاتصالية الإنترنت (فيركون، ور الإيكرونيكون).

ويرى كل من أبو غريب وعصام (199V) و وعبدالحي

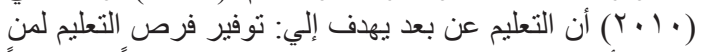

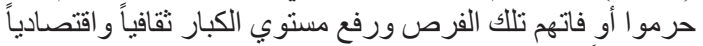

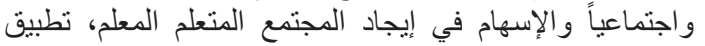

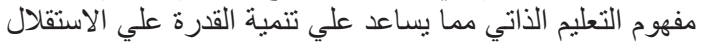
في تحصيل المعرفة، تخفيف الضغط علي التئي المؤسسات التعليمية،

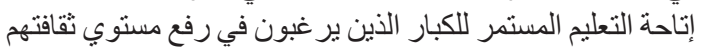

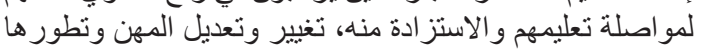

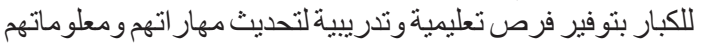

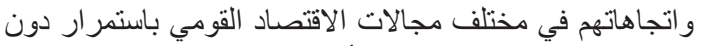

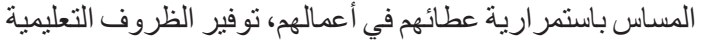

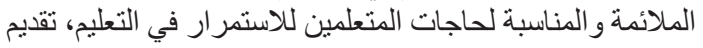

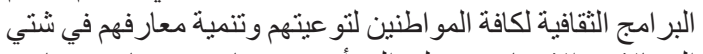

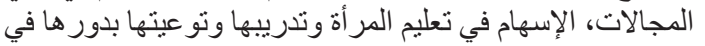

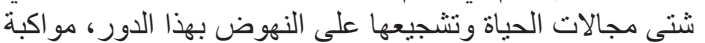

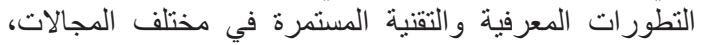
الإسهام في محو الأمية وتعليم الكبار.

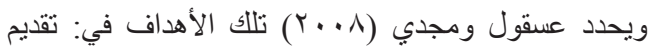

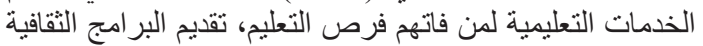

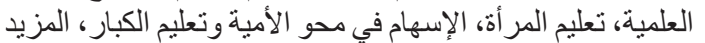

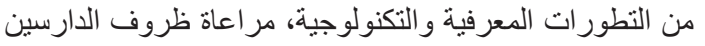
التعليمية.

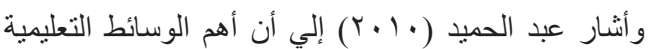

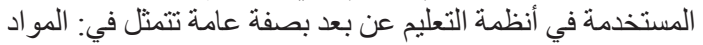

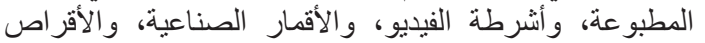

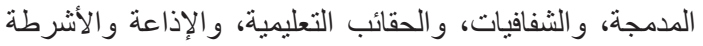

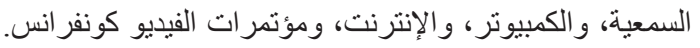
كما لخص فيردوين وكلارك (1990) Verduin \& Clark الوسائط التي يمكن استخدامها في التعليم عن بعد في: الوسائط

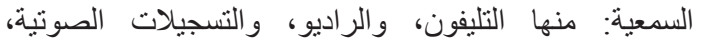

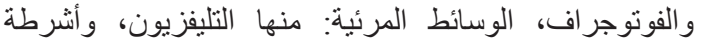
الفيديو، الحاسب الآلي وبر امجهاه، المطبو عات.

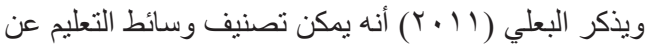

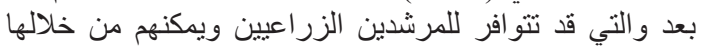

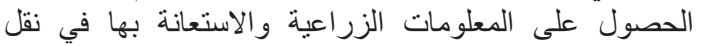

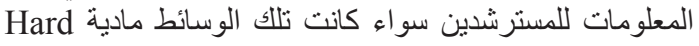

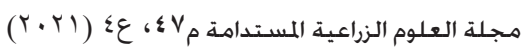

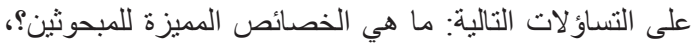

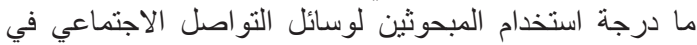

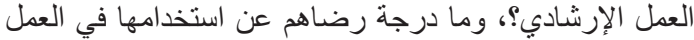

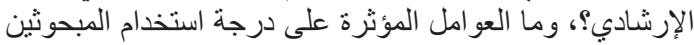

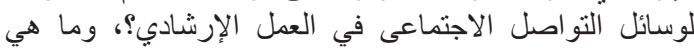

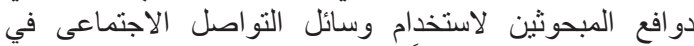

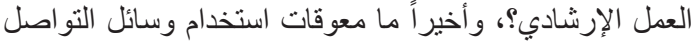

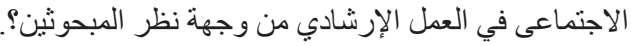

أهداف البحث

يستهدف هذا البحث بصفة رئيسية التعرف على استخدام

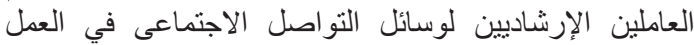

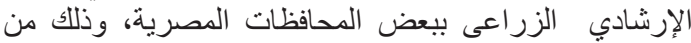
خلال تحقيق الأهداف الفر عية التالية:

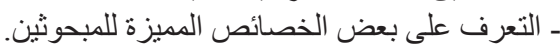

ـ التعرف على درجة استخدام ورصا المبحوثين عن وسائل التواصل الاجتماعي في العمل الإرشادي.

- تحديد العو امل المؤثرة على درجة استخدام المبحوثين لوسائل

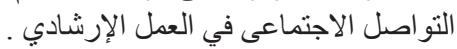

- التعرف على دوافع استخدام المبحوثين لوسائل التواصل

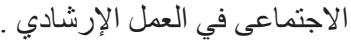

ـ التعرف على معوقات استخدام وسائل التو اصل الاجتماعى في العمل الإرشادي من وجهة نظر المبحوثين.

الاستعر اض المرجعى

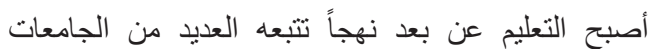

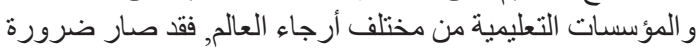

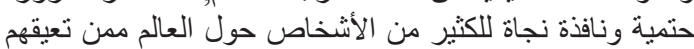

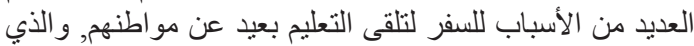

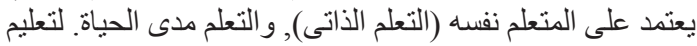

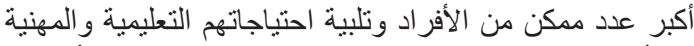
كما أنه لا يتقيد بمكان وزمان معينين الأر ولاد ولا بفئة معينة من الأفر اد.

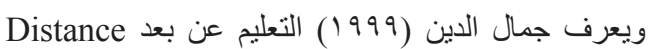

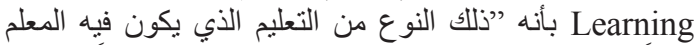

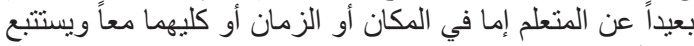

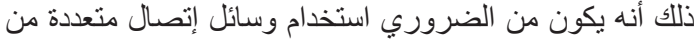

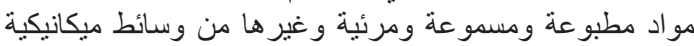

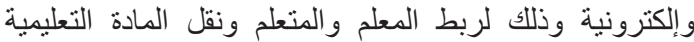

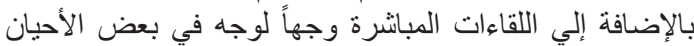

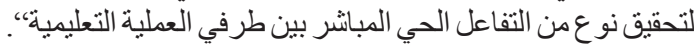

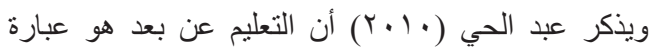

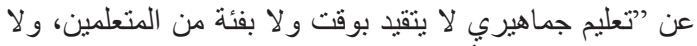

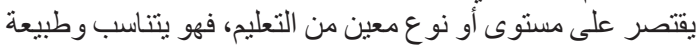

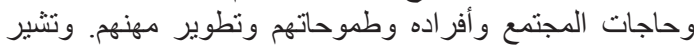

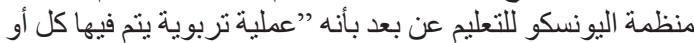

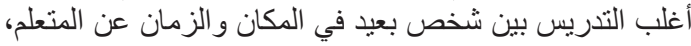


للتعامل مع تكنولوجيا المعلومات و الاتصاليات.

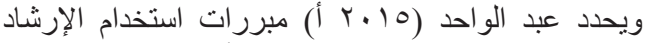

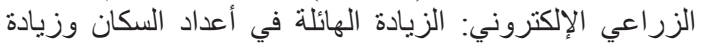

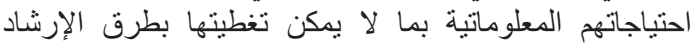

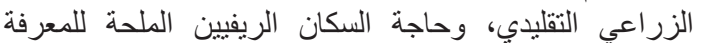

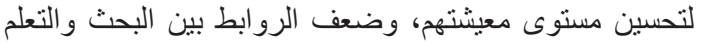
و الإرشاد مما يعوق التغيير التكنولوجي ويصعب التوبن التغلب عليه

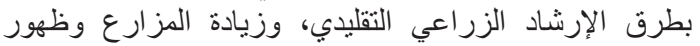

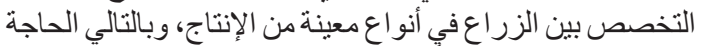

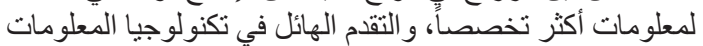

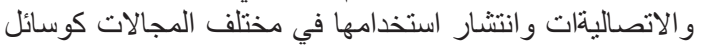

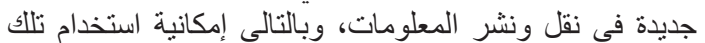

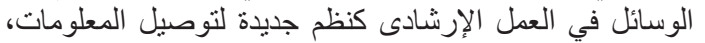

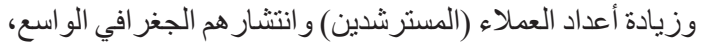

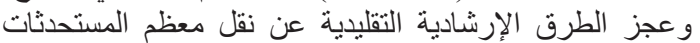
الزر اعية (التي تبتكر غالباً خارج المجتمع) التفلية

يذكر عبد الواحد (10 • بأ) أن هناك العديد من أوجه القصور

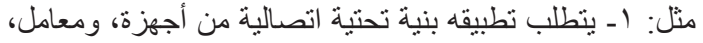

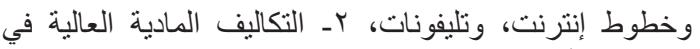

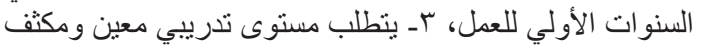

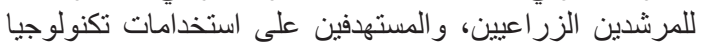

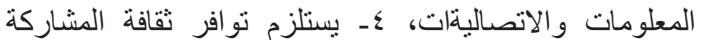
و الحوار و النقد لاى المستخدمين، و الوعى الوعلى الكافي بأهمية استخدام

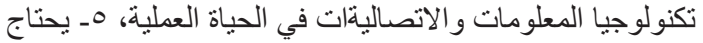

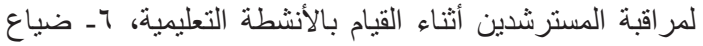

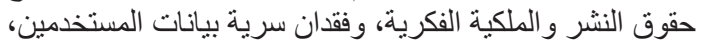

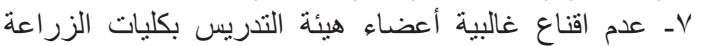

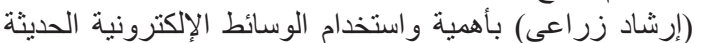

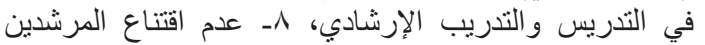

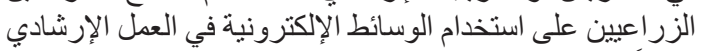

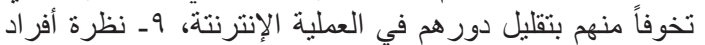

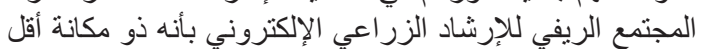

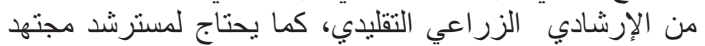

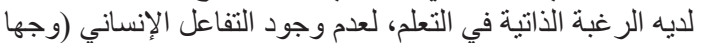

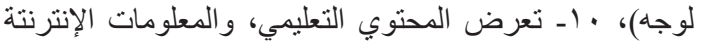

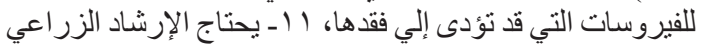

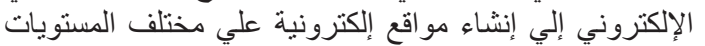

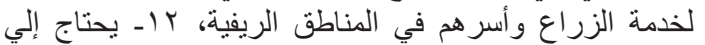

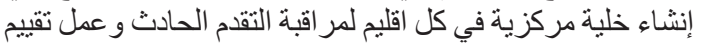
مستمر لأنشطة الإرشاد الزر اعي الإلكتروني.

Social Network بطلق مصطلح الثبكات الاجتماعية

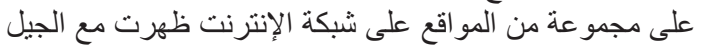

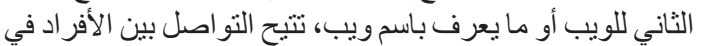

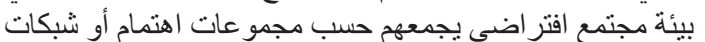

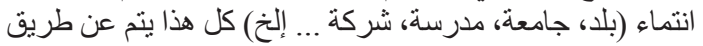

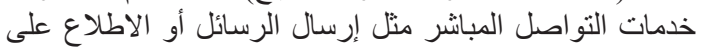

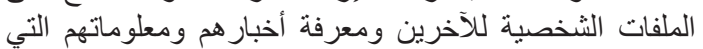

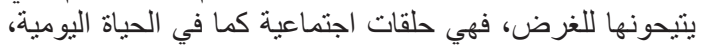

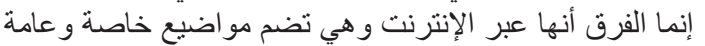

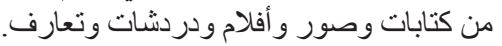

كالمطبو عات الإنترنتة وشر ائط الكاسيت أو غير مادية Ware Soft Ware

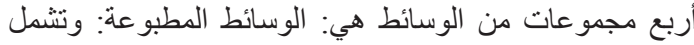

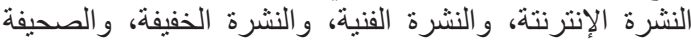

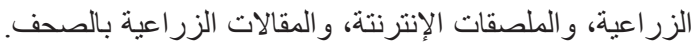

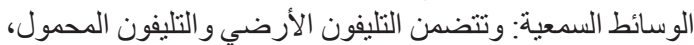

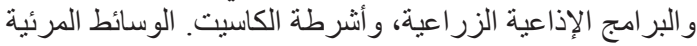

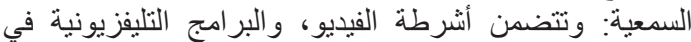

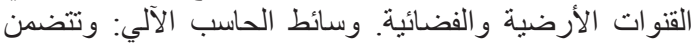

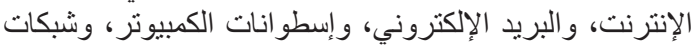

الاتصالية الإنترنت (فيركون، ور الإيكون، والنيطن).

ويعرف قشطه (Y (Y) الإرشاد الزراعي الإلكتروني بefinition Of E- Extension

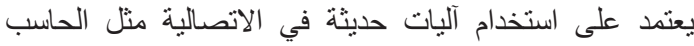

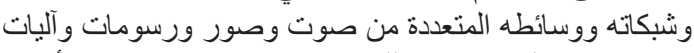

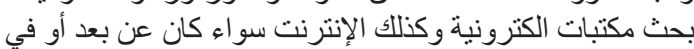

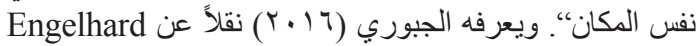

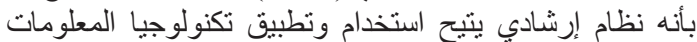

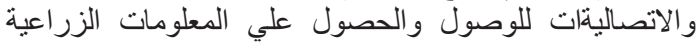

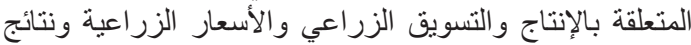
الأبحاث الزر اعية و المستحدثات الزر اعية الزية، لزيادة مستوي الإنتاجية الزية

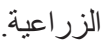

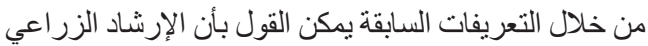

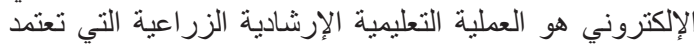

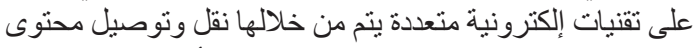

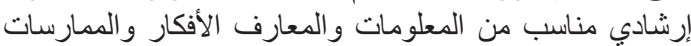
و التكنولُوجيا الزر اعبة الحديثة إلي الفئات المستهدفة في بيئة مناسبة.

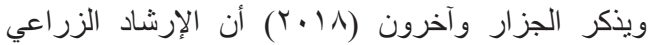

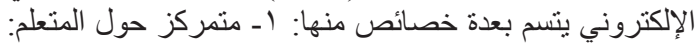

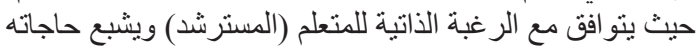

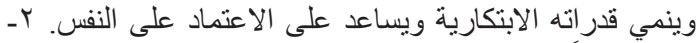

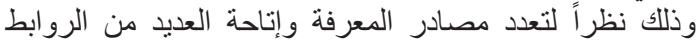

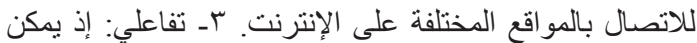

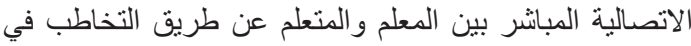

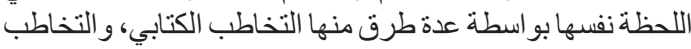

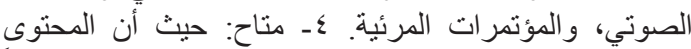

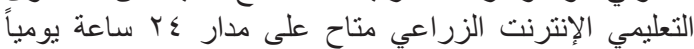

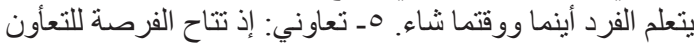

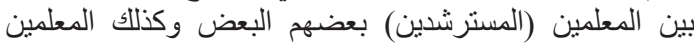

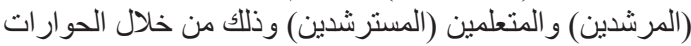

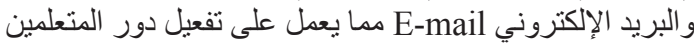

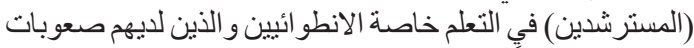
في التعامل وجهاً لوجه مع الآخرين. وتحديث المحتوي العلمي بما يتو افق مع منطلبات العصر العر.

ويشير عبدالو احد (10 ـ ب أ) إلى أن المكونات الأساسية لإرشاد

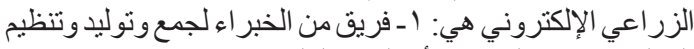

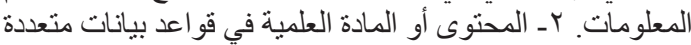

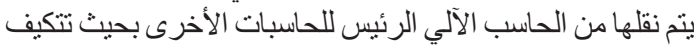

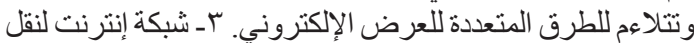

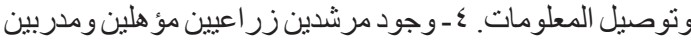

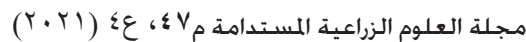




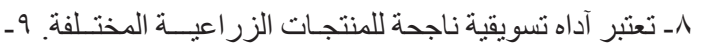

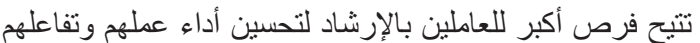

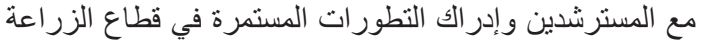

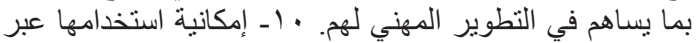

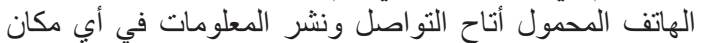

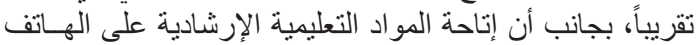

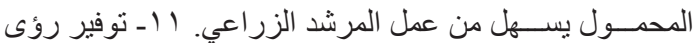

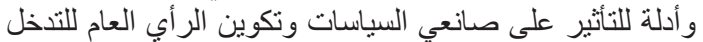

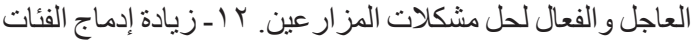

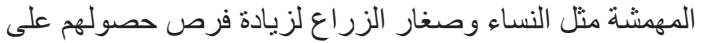

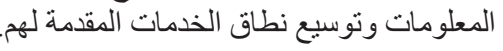

وتتمثل بعض أنواع مواقع التّواصُل الاجتماعيّ كالآتي:

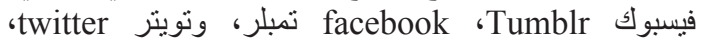

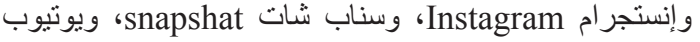

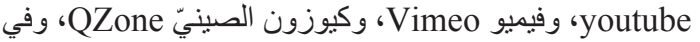

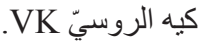

و أجريت بعض الدر اسات في هذا الصدد كدر اسة عبد الو احد

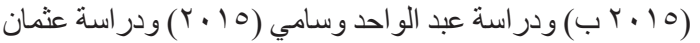

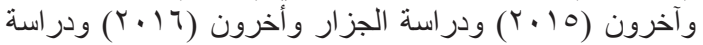

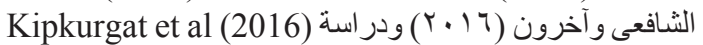

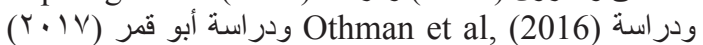

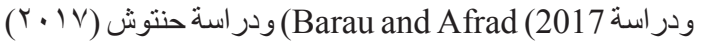

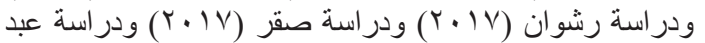

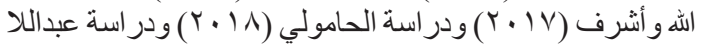

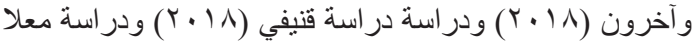

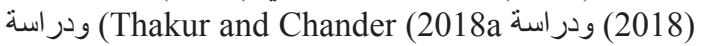

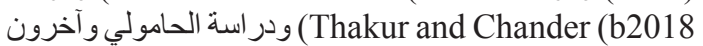

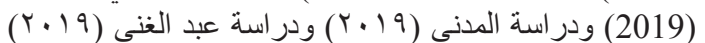

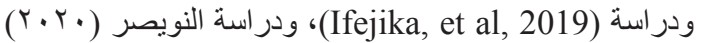

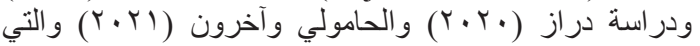

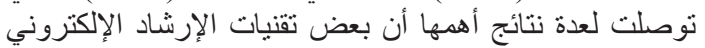

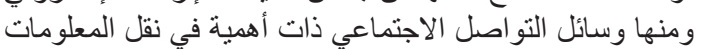

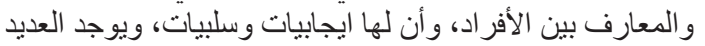

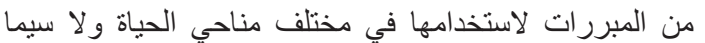

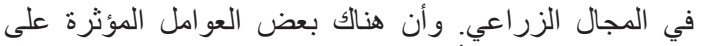

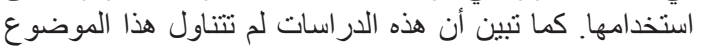

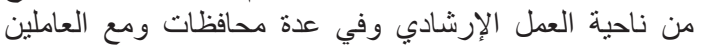

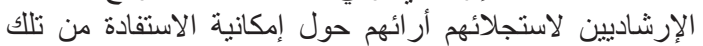
الوسائل في العمل الإرشادي.

الأسيلوب البحثى

أو لاً: التعاريف الإجر ائية:

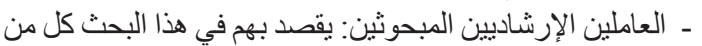

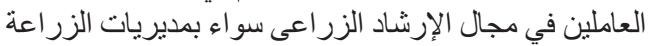

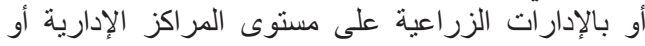

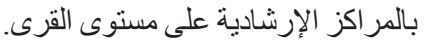

ـ السن: ويقصد به عمر المبحوث حتى وقت جمع البيانات, وتم قياسه بالعدد الخام لسنو ات عمر المبحوث.

ـ عدد أفر اد الأسرة: يقصد به عدد أفر اد أسرة المبحوث وقت جمع

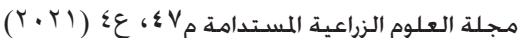

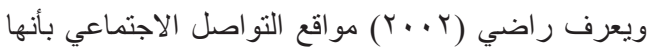

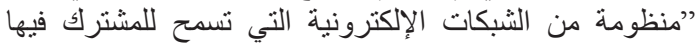

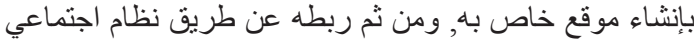
إلكتروني مع أعضاء آخرين لديهم الاهنمامات ونه و الهو ايات نفسها. www. kse org kw1 Mohardesoon/issue 113))

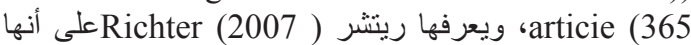

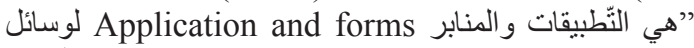

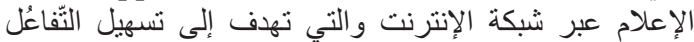

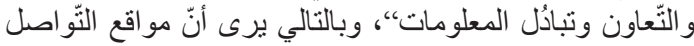
الاجتماعي هي قاعدة معلو ماتية ووسيلة إعلامية.

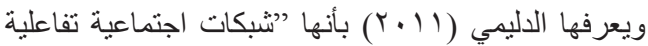

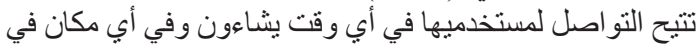

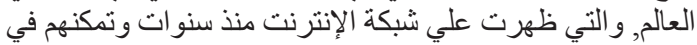

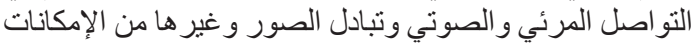

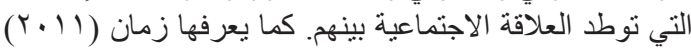

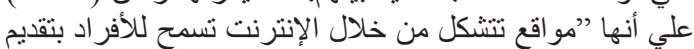

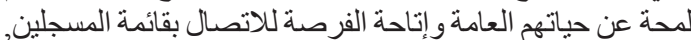
و التعبير عن وجهة نظر الأفراد أو المجموعات من خل خلال عملية الاتصالية, وتختلف طبيعة التو اصل من موقع لآخر.

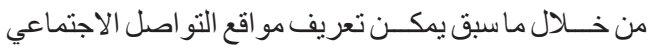

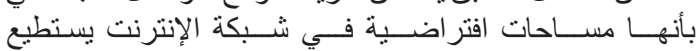

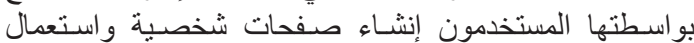

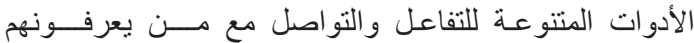

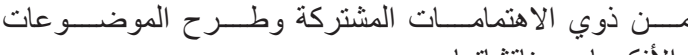
و الأفكــار ومناقثناتها.

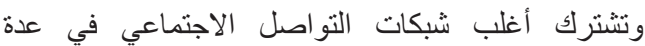

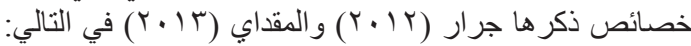

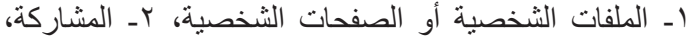

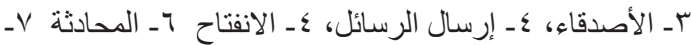

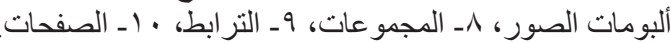

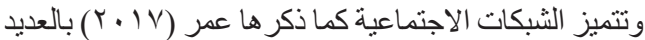

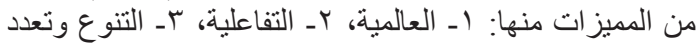

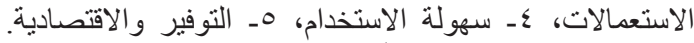

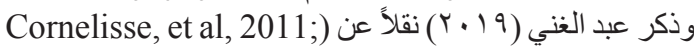
Gharis, et al, 2014; Saravanan 2017; Thakur and (Chander, 2018 and Bhattacharjee

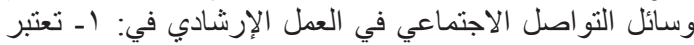

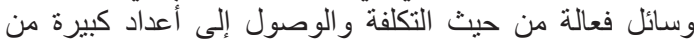

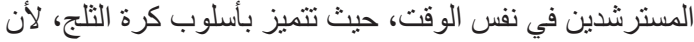

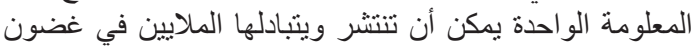

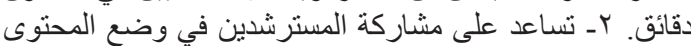

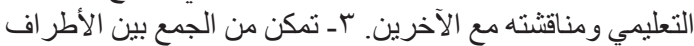

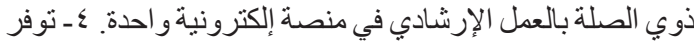

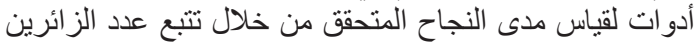

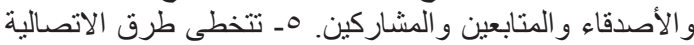

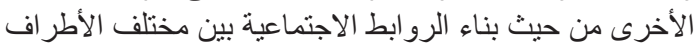

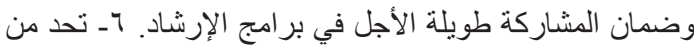

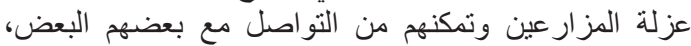

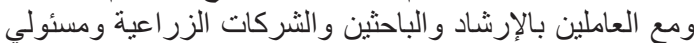

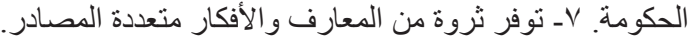


جمعت درجات المحورين لتعبر عن هذا المتغير.

ـ الاتجاه نحو استخدام وسائل التواصل الاجتماعي في العمل

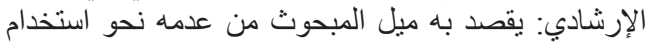

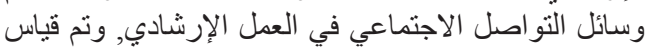

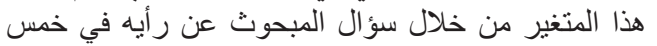

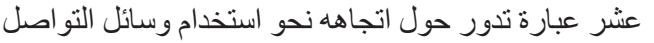

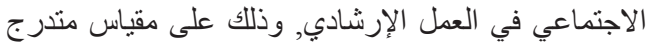

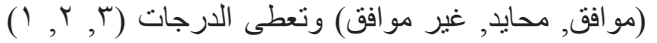

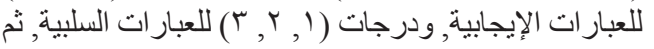
جمعت هذه الدرجات لتعبر عن هذا المتغير.

- استخدام الأجهزة التكنولوجية في الاخول على مواقع التو اصل

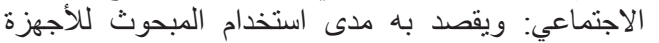

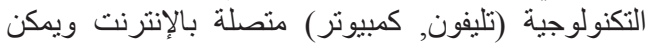

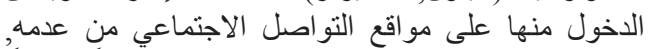
وذللك بسؤال المبحوث على على مقياس متدرج (دائماً, أحياناً,

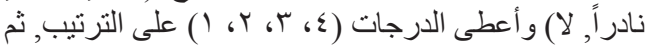
جمعت هذه الدرجات لتعبر عن هذا المتغير.

- استخدام وسائل التو اصل الاجتماعي في العمل الإرشادي: وتم

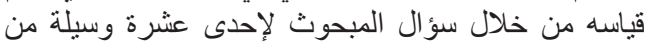

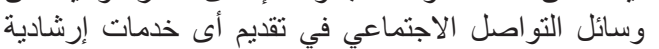

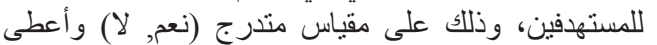

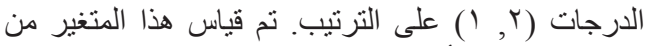

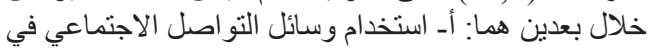

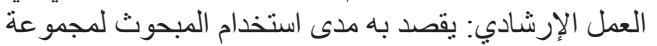

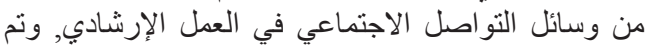

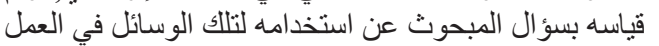

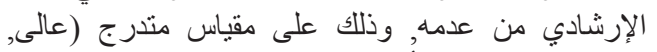

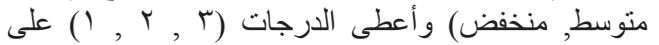

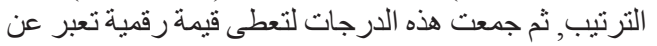

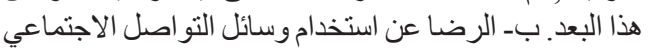

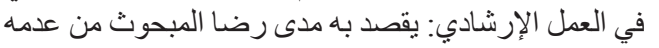

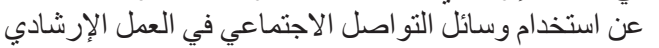

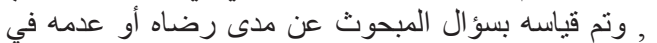

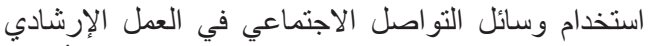

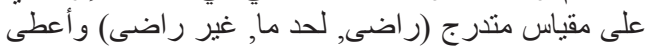

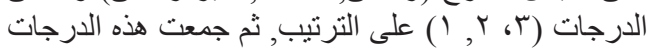

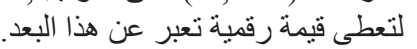

- دو افع استخدام وسائل التو اصل الاجتماعي في العمل الإرشادي:

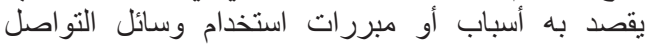

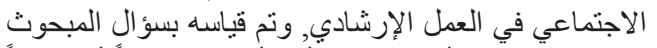

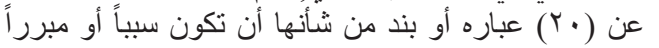

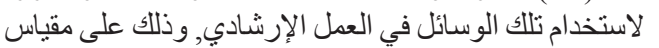

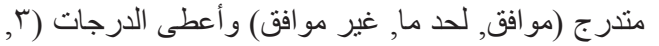
r

ـ معوقات استخداموسائل التو اصل الاجتماعي في العمل الإرشادي:

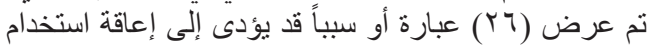

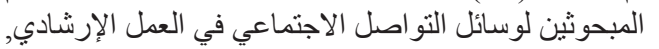

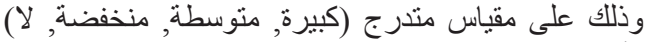

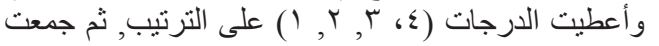

البيانات، و عبر عنه بالعدد الخام لأفر اد الأسرة.

- الحالة التعليمية: يقصد به الدرجة العليمية الحاصل عليها

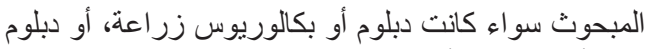

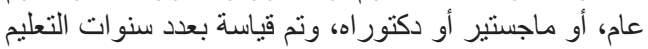

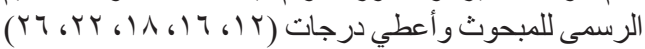
على الترتيب.

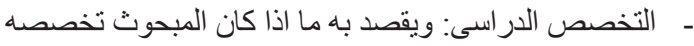

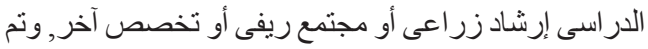

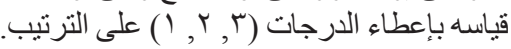

- الخبرة الوظيفية: يقصد بها المدة التى قضاها المبحوث بالعمل في تللك الوظيفة حتى وقت جمع البيانات معبر أ عنها بعدد السنو ات بات.

الخبرة الإرشادية: يقصد بها المدة التى قضاها العاملين

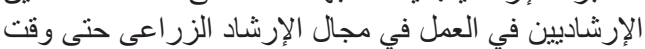
جمع البيانات معبر اً عنهاً بعدد السنوات الإن.

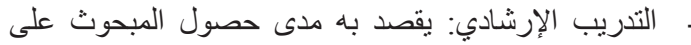

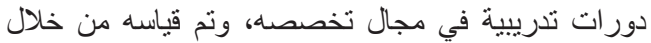

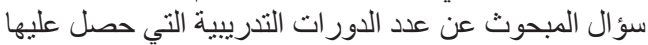
المبحوث في مجال الإرشاد الزر اعي.

- التدريب في مجال تكنولوجيا المعلومات و الاتصاليةات: ويقصد

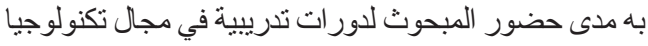

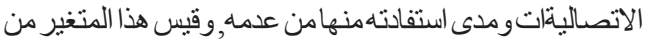

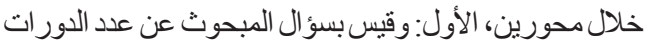

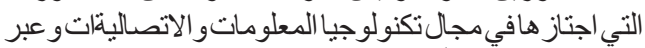

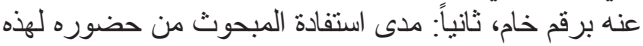

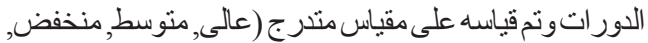

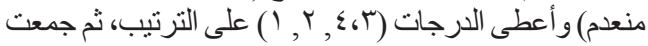
هذه الارجات لتعبر عن هذا المتغير.

ـ المعرفة ببعض برمجيات الحاسب الآلي: يقصد به مدى معرفة

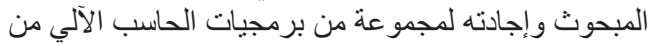

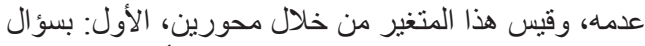

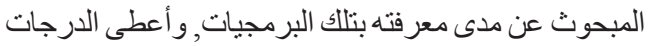

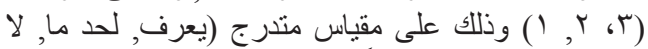

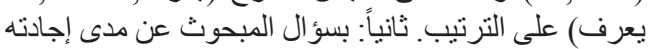

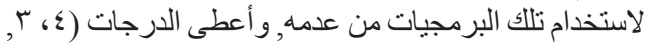

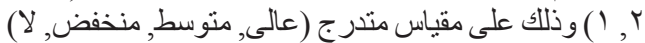
على الترتيب, ثم جمعت هذه الدرجات لتعبر عن هذا المتغير.

- المعرفة بوسائل التواصل الاجتماعي: يقصد بها مدى معرفة

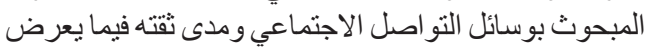

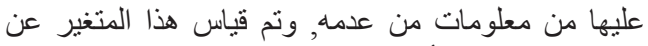

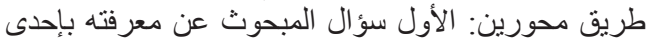

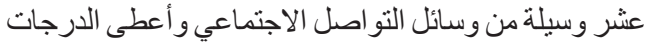

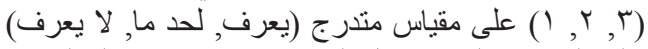

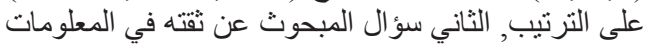

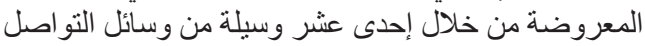

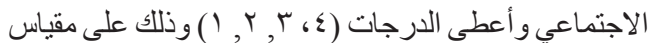
متدرج (عالى, متوسط, منخفض, منعدم) على الترتيب, ثم

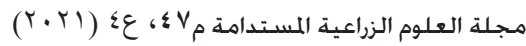




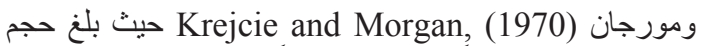

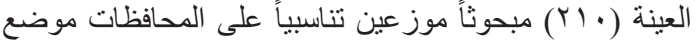

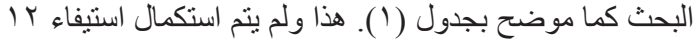

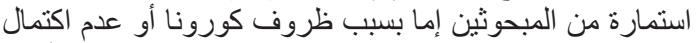

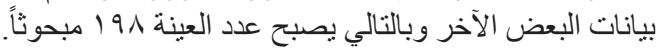

$$
\text { خامساً: أسلوب جمع وتحليل البيانات: }
$$

تم إعداد إستمارة إستبيان مناسبة لهذا الغرض تمانيان تم عرضها

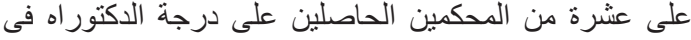

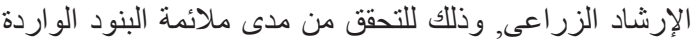

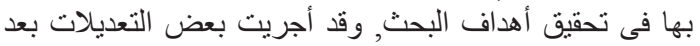

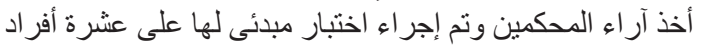

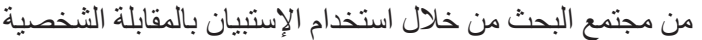

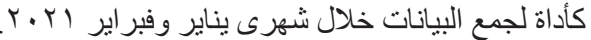

بعد عملية جمع البيانات تم مراجعتها وتفريغها وجدولتها

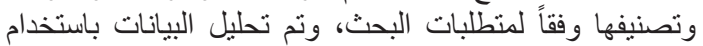

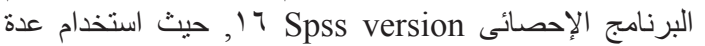

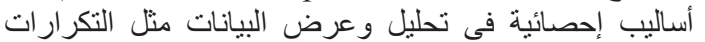

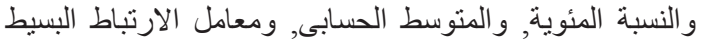

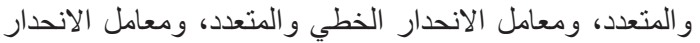

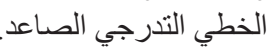

النتائج ومناقشتهها

أو لاً: بعض الخصائص المميزة العاملين الإرشاديين المبحوثين:

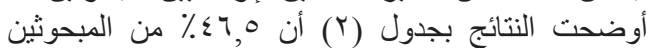

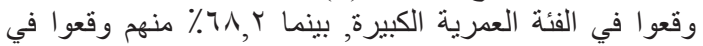

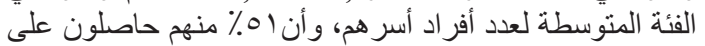

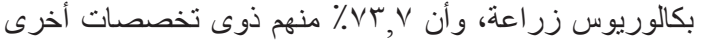

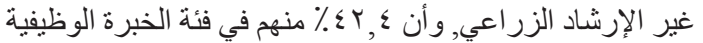

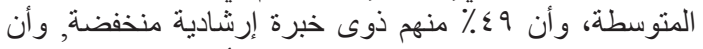

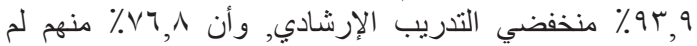

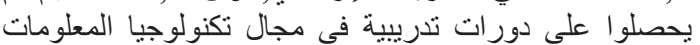

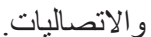

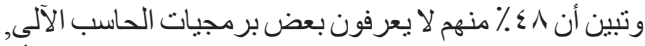

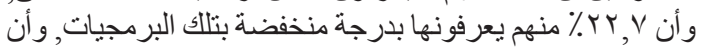

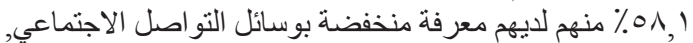

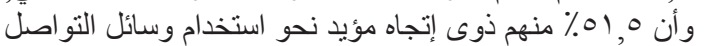

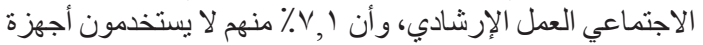

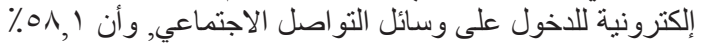

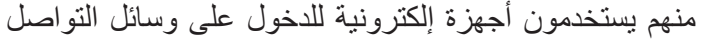

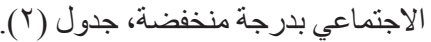

بناءاً على ما سبق يتضح تقدم أعمار غالبية المبحوثين

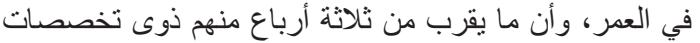

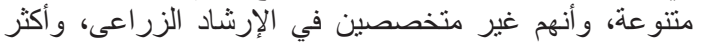

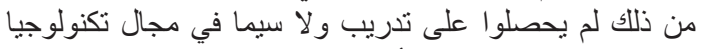

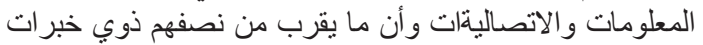

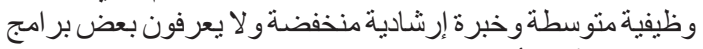

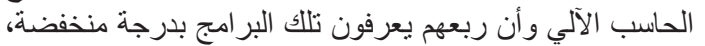

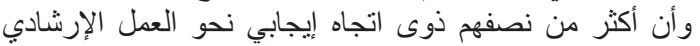
ويستخدمون أجهزة إلكترونية للاخول لوسائل التو اصل الاجنماعي الإني

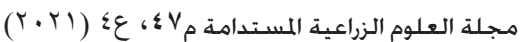

استجابات المبحوثين عن كل عبارة أو سبب.

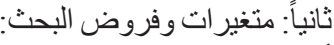

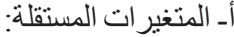

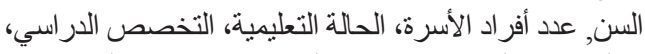

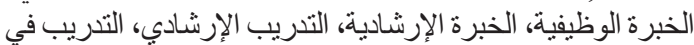

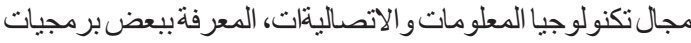

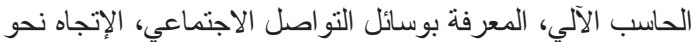

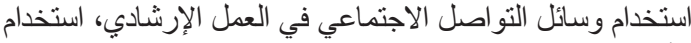
الأجهزة الإلكترونية في الدخول على مو اقع التو اصل الاجني الإنماعي.

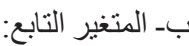

تمثن المتغير التابع في هذا البحث في "استخدام وسائل التو اصل الاجتماعي في العمل الإرشادي، فئ.

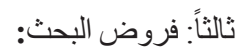

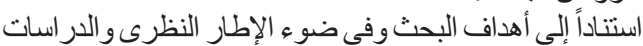

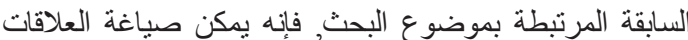

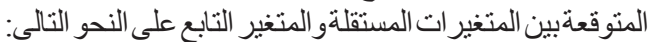

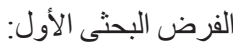

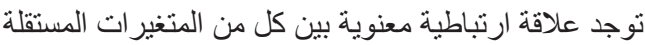

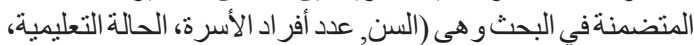

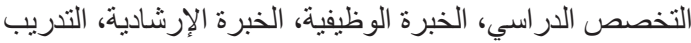

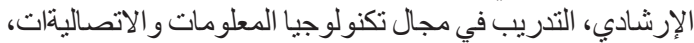

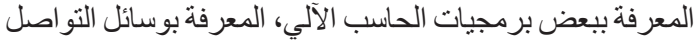

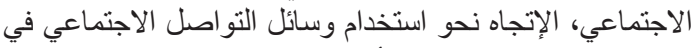

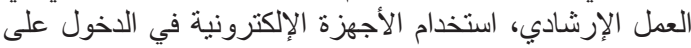

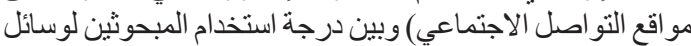
التو اصل الاجتماعي في العمل الإرشادي كمتغير تابع.

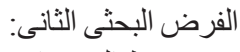

ترتبط المتغيرات المستقلة المدروسة مجتمعة بدرجة استخدام المبحوثينلوسائل التو اصل الاجتماعيفي العمل الإرشاديكمتغنير تابع.

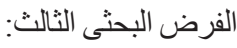

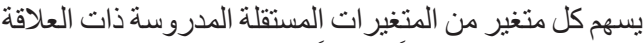

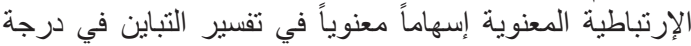

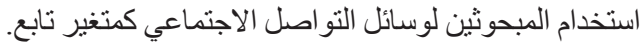

هذا وقد تم اختبار هذا الفروض في صورتها الصفرية (فرض

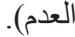
ر رابعاً: منطقة وشاملة و عينة البحث: أ: منطقة البحث:

تم تحديد المجال الجغرافى لهذا البحث في اختيار ثناث

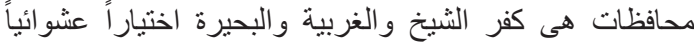

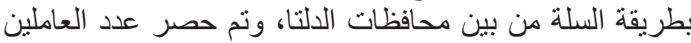
الإرشاديين في مجال الإرشاد الزر اعى بكل بكل منها.

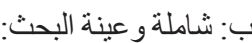
تم حصر العاملين الإرشاديين بالمحافظات الثثلاث المختارة

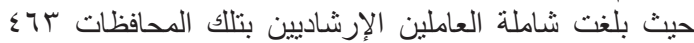
مبحوثاً، ولتحديد حجم العينة تم استخدام دعادلة كريجسى الإني 
جدول ( ) ) توزيع شاملة وعينة المبحوثين على المحافظات الثلاث موضع البحث .

\begin{tabular}{|c|c|c|c|c|c|}
\hline الإجمالي & البحيرة & الغربية & كفر الشيخ & المحافظات المختارة & 5 \\
\hline$\sum \pi$ & r. & 171 & 94 & الشاملة & 1 \\
\hline rI. & 90 & vr & $\varepsilon r$ & العينة & r \\
\hline
\end{tabular}

جدول (ץ) توزيع المبحوثين وفقاً لبعض الخصائص المميزة لهه.

\begin{tabular}{|c|c|c|c|c|c|}
\hline$\%$ & العدد & Vـ التدريب الإرشادي & $\%$ & العدد & 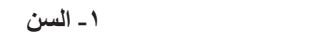 \\
\hline 95,9 & 1114 & 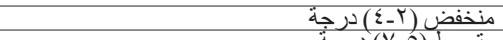 & 19,5 & ra & صغير (آ- •؟) سنة \\
\hline 0,1 & 1. & متوسط (V-0) درجةٌ & $r \leqslant, r$ & 71 & متوسط (إ - م) سنّة \\
\hline $1,$. & & مرتفع (1)-(1) درجة & $\sum 7,0$ & 91 & 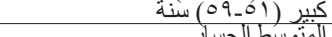 \\
\hline & & الاتئو اف المسابيى & رجذة & . & المنوسط الحسابي \\
\hline & & 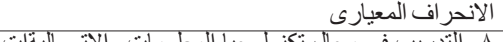 & & & الانحر اف المعيارى \\
\hline$\%$ & 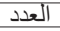 & يـ التدريب في مجال تكنولو جيا المعلومات والاتصالية|ت & $\%$ & العدد & - ـ ـ عدد أفر اد الأسرة \\
\hline $\mathrm{V}, \mathrm{A}$ & $10 \mathrm{r}$ & لم يتدريب & $r, r$ & ז & صغيرة (1 -ـ) فرد \\
\hline $1 \leqslant 27$ & r9 & تدرب: قليل (r-s) دورة & $71, \mathrm{r}$ & 150 & متوسطة (1_0) فرد \\
\hline 0,4 & 11 & مت متوسط (V-0) دورة & $\because 0$ & 1 & كبيره(1K-9) فرد \\
\hline$\vec{a}$ & $\frac{1}{8}$ & المتو سط الحشباي (-19) دورة & & & المت سط الحسا \\
\hline جنجة & & الانحر اف المعبازي & 要 & Y人 & الالندر اف المعنابي \\
\hline & 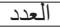 & 9 ـ المعر فة ببعض بر مجيات الحاسب الالى & $\%$ & العدد & 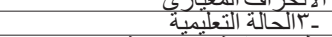 \\
\hline$\leqslant 9, \cdot$ & $9 \mathrm{~V}$ & لا لاعرف (صفر ) درجة & $\$ 1,0$ & AT & دبلوم زراعة (بأ) سنة \\
\hline YY, Y & «o & بعزف :منخفضة (1-1) درجةً & & 1.1 & بكالو ريوس زر اعة (7) آنة \\
\hline$Y \cdot, Y$ & \&1 & متوسطة (1/9-9) ذرجة & $1: 0$ & r & دبلومة علبا (1) سنّة \\
\hline$v, r$ & 10 & مرتفعة (1) (YO Y) درجة & $\xi$ & $\frac{1}{\xi}$ & 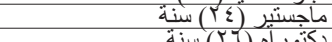 \\
\hline 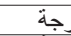 & & المتوسط الحسابى & رجة & AI & المتوسط الحسابي \\
\hline ج جة & & الانحر اف المعبازي & ج & & الانحر اف المعبازٍ \\
\hline$\frac{\%}{0.1}$ & ال العدد & 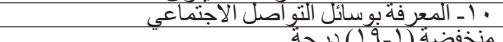 & $\%$ & آلعدد & 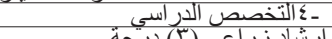 \\
\hline rT'T & $7 \varepsilon$ & 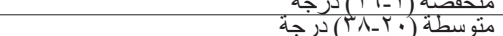 & $\because$ & $\varepsilon$ & 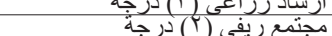 \\
\hline $9, \frac{2}{9}$ & 19 & 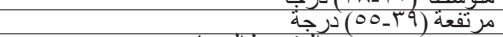 & $V^{2}, V$ & $1 \leqslant 7$ & تخضص آخي (1) درجة \\
\hline \multicolumn{2}{|c|}{ 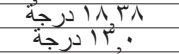 } & الإلنتو سط الحسابي & & & أل ألمتوسط الحسابح \\
\hline$\%$ & العدد ', & جاه نحو استخدام وسائل الثُواصل & 1. & العدد & 19 \\
\hline
\end{tabular}

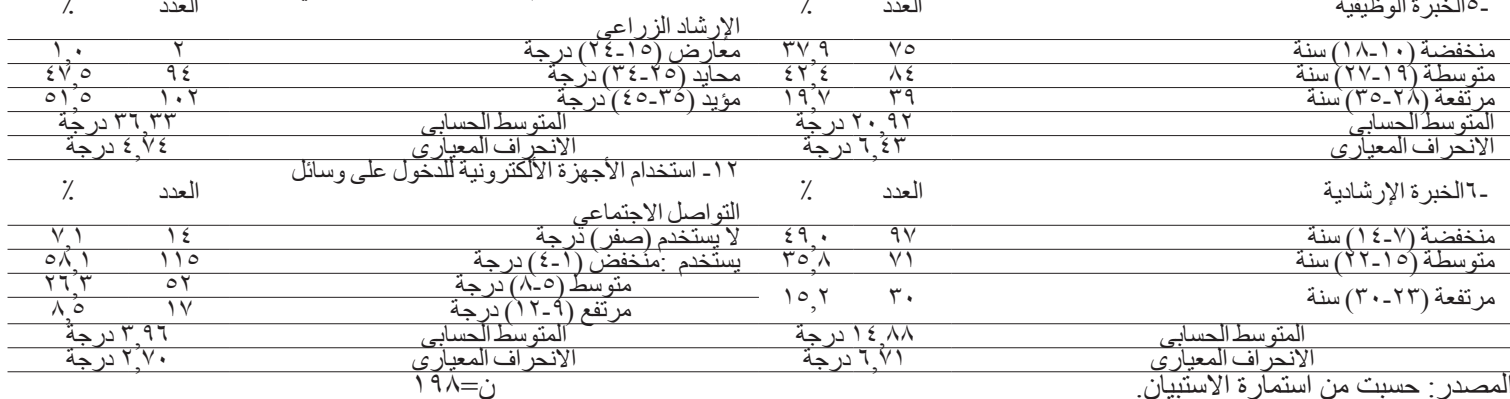

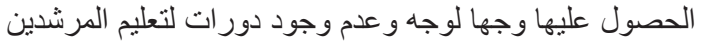

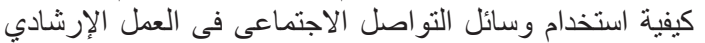

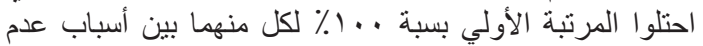

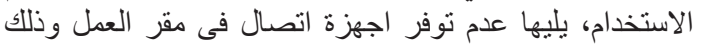

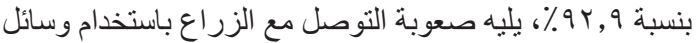

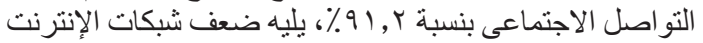

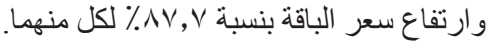

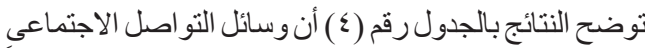

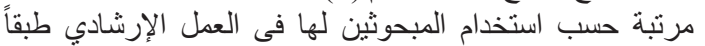

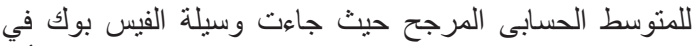

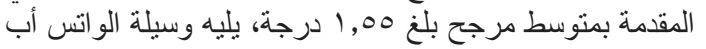

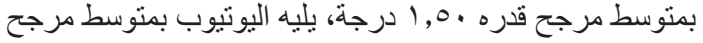

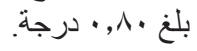

ثالثاً: رضا العاملين الإرشاديين المبحوثين عن استخدامهم لوسائل التو اصل الاجتماعى فى العمل الإرشادي: العادي:

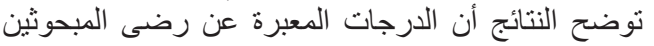

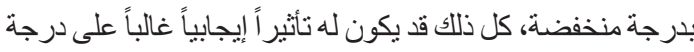
استخدامهم لوسائل التو اصل الاجتماعي في العمل الإرشادي.

ثانياً: درجة استخدام العاملين الإرشاديين المبحوثين لمو اقع التو اصل الاجتماعي في العمل الإرشادي:

تشير النتائج إلى أن الدرجات الإنداتئ المعبرة عن استخدام المبحوثين

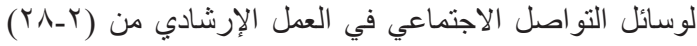

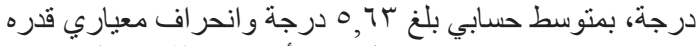

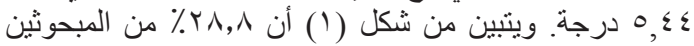

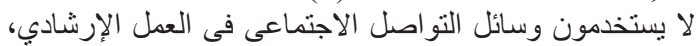

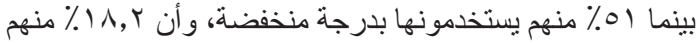

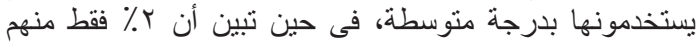

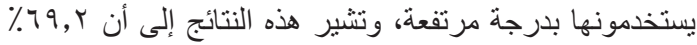

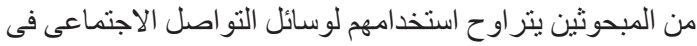
العمل الإرشادي بين المنخفض وارين المنتوسط.

وكان من أهم أسباب عدم استخدام المبحوثين فتشير النتائج بجدول (r) إلى أن عدم ثقة الزراع في أى معلومة إلا من خلال

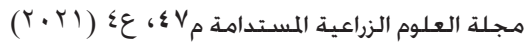




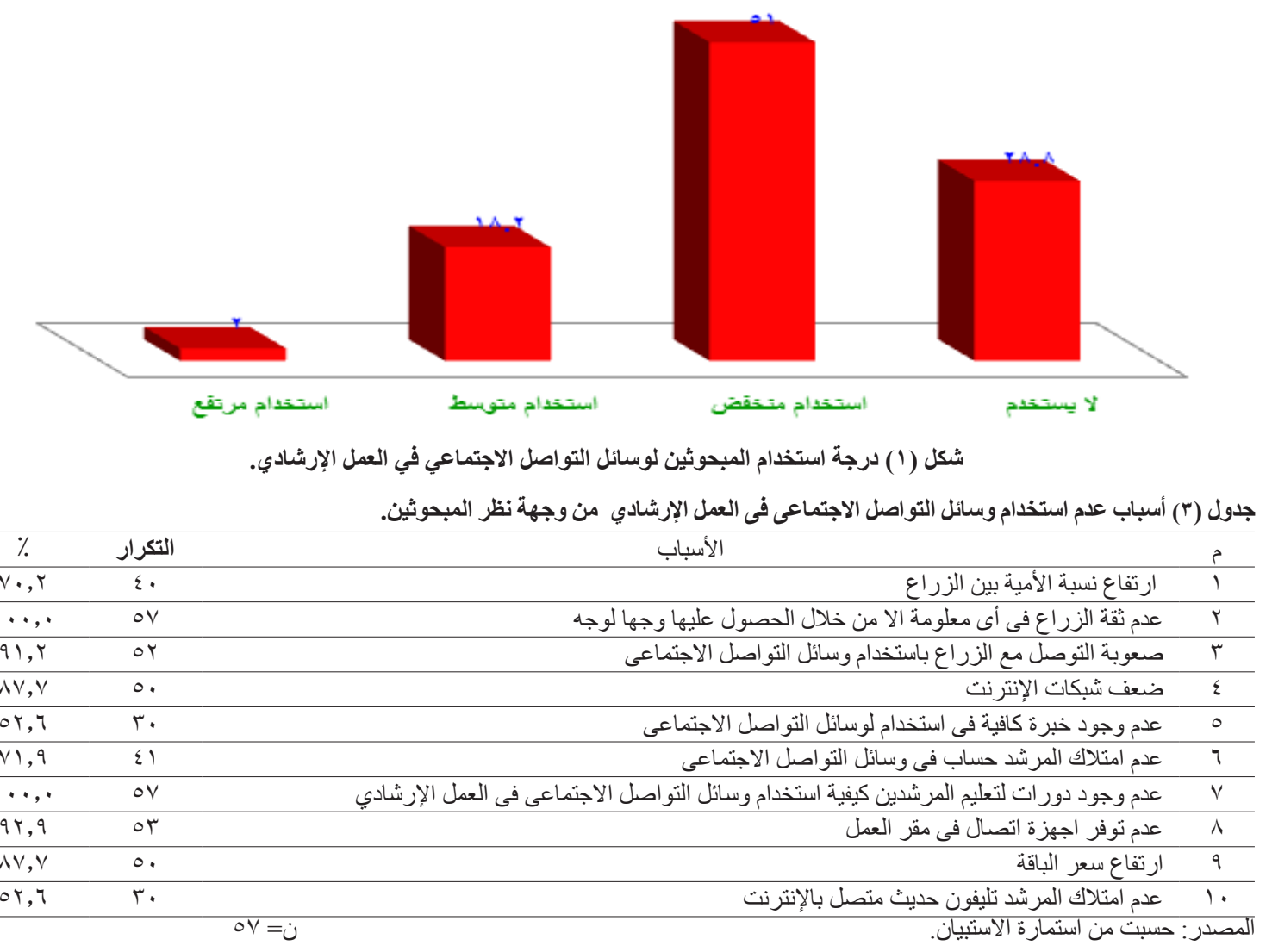

جدول (؛) توزيع المبحوثين وفقاً للرجة استخذامهم وسائل التواصل الاجتماعى فى العمل الإرشادي.

\begin{tabular}{|c|c|c|c|c|c|c|}
\hline \multirow{2}{*}{ المتوسط } & \multicolumn{4}{|c|}{ درجة الاستخدام في العمل الإرشّادي } & \multirow{2}{*}{ الوسيلة } & \multirow[b]{2}{*}{ P } \\
\hline & لا يستخذم & منخفض م من & متّوسط & عالى & & \\
\hline 1,00 & 79 & $1 \varepsilon$ & 01 & $T \leq$ & فيس بوك & 1 \\
\hline $1,0$. & $V \varepsilon$ & 19 & ri & 79 & و و اتس أب & r \\
\hline$\cdot, \wedge$ & TKt & r. & rA & rA & بوبتيوب & $r$ \\
\hline., ro & 109 & IV & is & 1. & توتينز & $\varepsilon$ \\
\hline$\cdot, \Gamma \leqslant$ & 171 & 17 & 11 & 1. & إنستجر اد & 0 \\
\hline$\cdot, \varepsilon \leqslant$ & $10 \mathrm{~V}$ & 11 & ir & $1 \wedge$ & 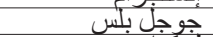 & 7 \\
\hline., 11 & 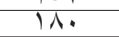 & $1 \leqslant$ & $\varepsilon$ & $\cdot$ & 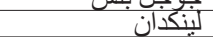 & $\mathrm{v}$ \\
\hline., $1 \mathrm{~T}$ & IA. & ir & 0 & 1 & فأبير & $\Lambda$ \\
\hline., 1 & TAY & IT & r & 1 & لآين & 9 \\
\hline., $1 \mathrm{r}$ & $1 \times 9$ & IE & 0 & . & تبلك توك & 1. \\
\hline$\cdot, 1$ & IAr & ir & $\varepsilon$ & . & سكايب & II \\
\hline
\end{tabular}

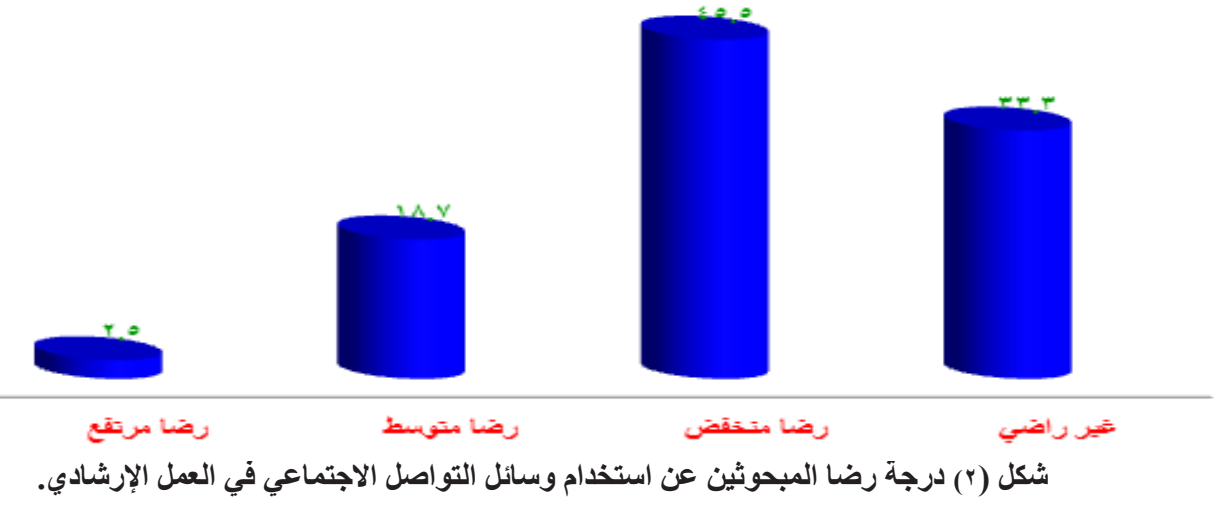

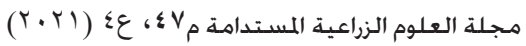


مبرر الوصول إلى أكبر عدد من المسترشدين فى وقت قصير جاء

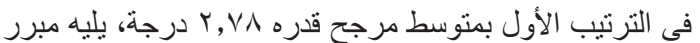

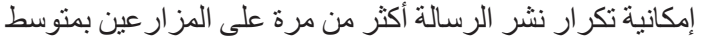

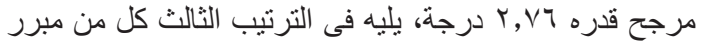

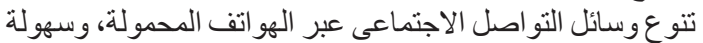

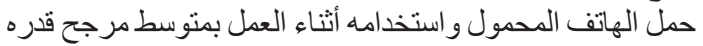

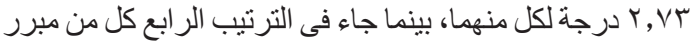

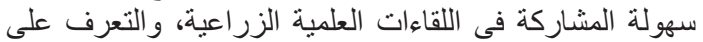

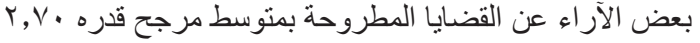

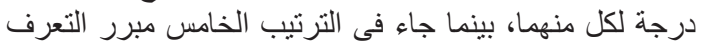

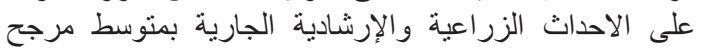

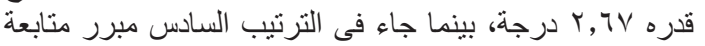

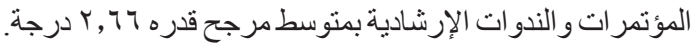

خامساً: معوقات استخدام العاملين الإرشاديين لمواقع التواصل الاجتماعي في العمل الإرشادي:

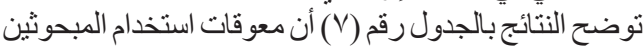

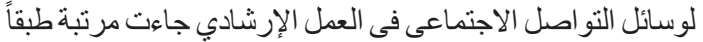

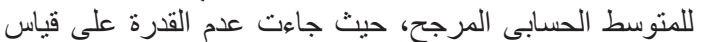

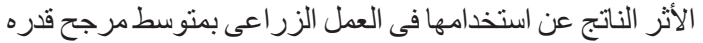

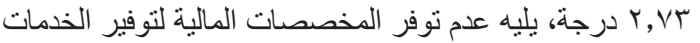

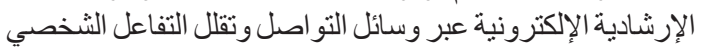

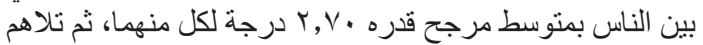

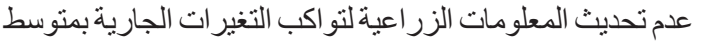

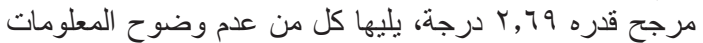

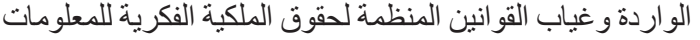

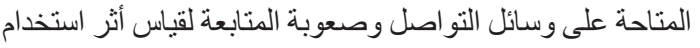

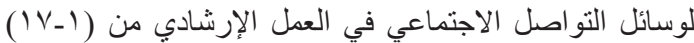

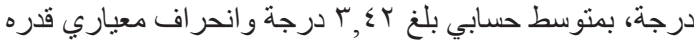

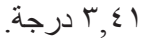

ويظهر من شكل رقم (Y) أن ؟, بr\% من المبحوثين المستخدمين

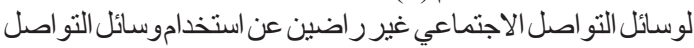

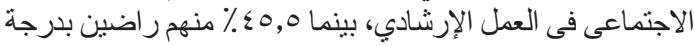

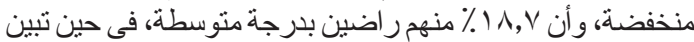

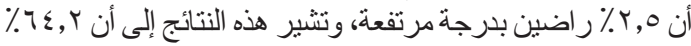

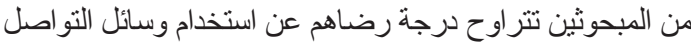

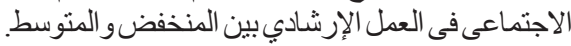

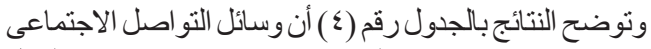

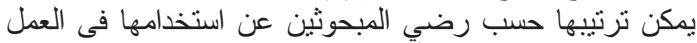

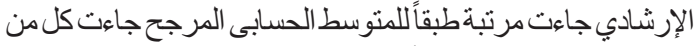

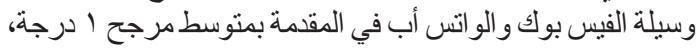

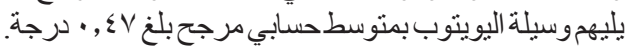

و هذه النتائج تعكس إمكانية تفعيل الاستفادة من وسيلتي

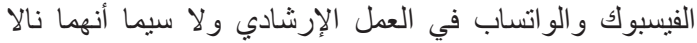

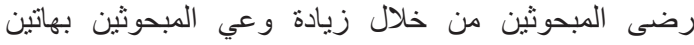
الوسيلتين وتدريبهر على كيفية تعظيم الاستفادة منهما.

رابعاً: دوافع استخدام العاملين الإرشاديين لمواقع التواصل الإقل

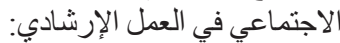

تشير النتائج بالجدول رقم (0) الإدئ إلى أن دو افع استخدام العاملين

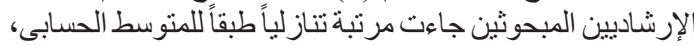

\begin{tabular}{|c|c|c|c|c|c|}
\hline \multirow{2}{*}{ المترسط } & \multicolumn{3}{|c|}{ درجة الرضى } & \multirow{2}{*}{ الوسيلة } & \multirow{2}{*}{$\hat{r}$} \\
\hline & غير راضى & لحد ما & راضى & & \\
\hline $1, \cdots$ & A. & rN & A. & فيس بوك & 1 \\
\hline$\cdot, \leqslant \vee$ & $1 T V$ & TV & $r \varepsilon$ & بوتيوب & $r$ \\
\hline$\cdot, 17$ & 187 & Ir & 1. & تويتر & $\varepsilon$ \\
\hline$\cdot, 11$ & $I V A$ & 11 & 9 & إنستجر ام & 0 \\
\hline$\cdot, .0$ & 19. & 7 & $r$ & فايير & 1 \\
\hline$\cdot, .0$ & 191 & $\varepsilon$ & $r$ & لاين & 9 \\
\hline., .0 & 119 & $\Lambda$ & 1 & تيك توك & 1. \\
\hline$\cdot, \cdot r$ & 194 & 0 & 1 & سكايب & 11 \\
\hline
\end{tabular}

جدول (†) توزيع المبحوثين وفقاً لدوافع استخدامهم وسائل التواصل الاجتماعى فى العمل الإرشادي.

\begin{tabular}{|c|c|c|c|c|c|}
\hline المرجح & غو افقر & لحد & 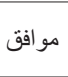 & دو افع الاستخدام & 5 \\
\hline r,VT & 7 & «1 & 101 & تنوع وسائل التو اصل الاجتماعي عبر الهو اتف المحمولة (فيس، واتس، ماسنجر ، تويتر). & 1 \\
\hline Y, Yq & rA & $\Lambda \varepsilon$ & $\Lambda \tau$ & انخفاض أسعار الهو اتف المحمولة مقارنة بالانتقال إلى كل مرشد زر اعى. & r \\
\hline T,O1 & $1 \mathrm{~T}$ & $\varepsilon \mp$ & $1 \pi \varepsilon$ & انخفاض تكلفة استخداد و سائل التو اصل الاجتماعي في العمل الإرشّادي. & $\Gamma$ \\
\hline t,YV & $\Lambda$ & rq & 101 & امكانية حفظ الرسائل الإرشادية على الهاتف المحمول. & $\varepsilon$ \\
\hline r,07 & 17 & $0 \leqslant$ & $1 \mathrm{TA}$ & و جو د شركات زر اعية ذات امكانيات لاستخدام و سائل التو اصل الاجتماعي مع مز ار عيها. & 0 \\
\hline T,V4 & 9 & $\varepsilon Y$ & IEV & 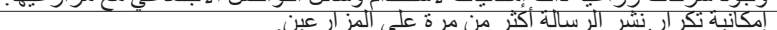 & 9 \\
\hline T,VA & 7 & $r \cdot$ & $17 \mathrm{r}$ & 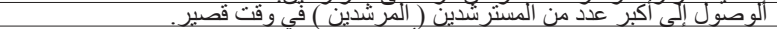 & $\mathrm{V}$ \\
\hline T,V & 0 & $\varepsilon r$ & 10. & سهو لة حمل الهاتف المحمول و استخدامه أثناء العمل الارتشادي. & $\Lambda$ \\
\hline T,IV & $\varepsilon \varepsilon$ & $\mathrm{VI}$ & $\mathrm{VA}$ & انخفاض نكلفة استخدام الانتر نت & 9 \\
\hline$r, \leqslant \leqslant$ & Y7 & ov & 110 & 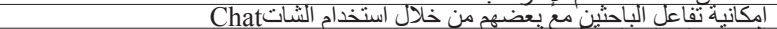 & 1. \\
\hline tili & r. & i) & $\mathrm{I} \cdot \mathrm{V}$ & 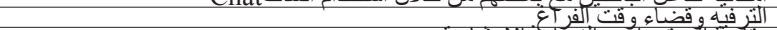 & II \\
\hline$T, 79$ & TI & $\varepsilon Y$ & $1 \leq \varepsilon$ & متابعة الموئمر ات و الندو آت & TY \\
\hline T,70 & 1. & $\varepsilon \lambda$ & $1 \xi$. & 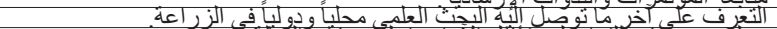 & IT \\
\hline Y,O & 11 & $\varepsilon 9$ & TII & 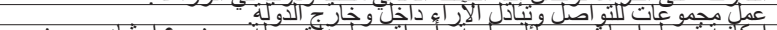 & 1 I \\
\hline T, & $\frac{\pi}{1}$ & हV & $\prod_{151}^{159}$ & 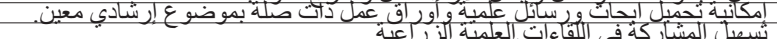 & 10 \\
\hline T, , & $\frac{1}{15}$ & हा & $\frac{11}{12 \lambda}$ & 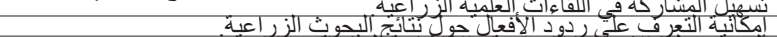 & $\frac{17}{17}$ \\
\hline T,TV & 9 & $\varepsilon \overline{7}$ & 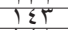 & 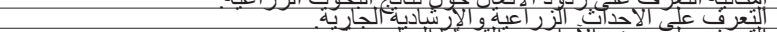 & $1 \mathrm{i}$ \\
\hline T,V. & $\lambda$ & $\sum T^{2}$ & $1 \varepsilon \lambda$ & 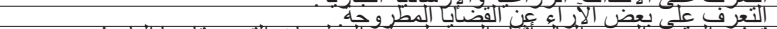 & 19 \\
\hline T,TE & 1. & 0. & ITि & 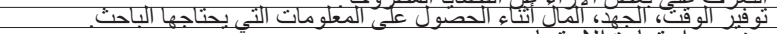 & r. \\
\hline
\end{tabular}


جدول (v) توزيع معوقات استخدام وسائل التواصل الاجتماعى فى العمل الإرشادي وفقاً لأراء المبحوثين.

\begin{tabular}{|c|c|c|c|c|c|c|}
\hline المرجح & ע & منففضة & متوسطة & كبيرة & المعوقات & م \\
\hline$r, 79$ & 1 & $\mathrm{~V}$ & $\varepsilon \Gamma$ & $1 \leqslant V$ & عدم تحديث المعلومات الزر اعبة لتو اكب التغبر ات الجارية. & 1 \\
\hline$T, T$ & 1 & $1 \cdot$ & 01 & 154 & 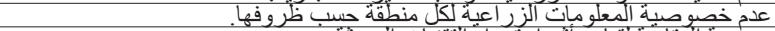 & \\
\hline T,TV & 1 & 11 & $\varepsilon \cdot$ & $1 \leq 7$ & 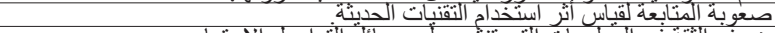 & $\Gamma$ \\
\hline$T, 0\}$ & 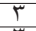 & 11 & 09 & Iro & 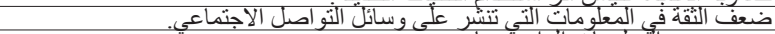 & $\varepsilon$ \\
\hline T,TV & 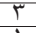 & 7 & 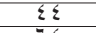 & $1 \leqslant 0$ & 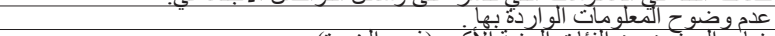 & 0 \\
\hline r,04 & 1 & 1.. & $7 \varepsilon$ & ITK & 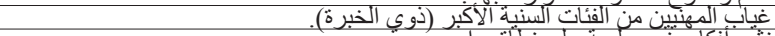 & \\
\hline$r, 00$ & $\underline{\varepsilon}$ & 15 & 0 : & 1,11 & نشر أفكار غنبر علمبة على نطأق واسع. & \\
\hline T,04 & r & 15 & or & $15 \cdot$ & 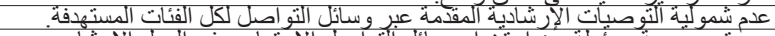 & \\
\hline$\frac{1,70}{T, 7 T}$ & $\frac{1}{1}$ & $\frac{1}{0}$ & 01 & $\frac{149}{150}$ & 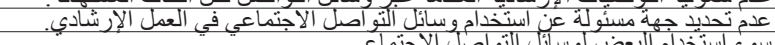 & 9 \\
\hline$t, T \mathrm{~T}$ & 1 & $\Lambda$ & $\leqslant 4$ & $1 \leqslant \pi$ & 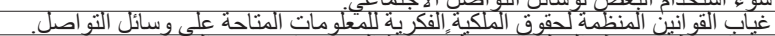 & 11 \\
\hline $\begin{array}{r}r, 7 \varepsilon \\
, y\end{array}$ & r & $\mathrm{V}$ & 01 & $1 \Gamma \mathrm{A}$ & 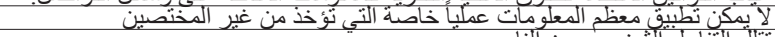 & II \\
\hline t,i. & i. & 9 & $\varepsilon 1$ & $\frac{1 \leq \Lambda}{1 \leqslant y}$ & 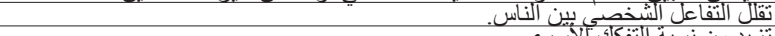 & $\frac{14}{14}$ \\
\hline $\begin{array}{r}r, 74 \\
, 74 \\
\end{array}$ & 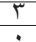 & $\frac{7}{14}$ & Or & $\frac{150}{15 V}$ & 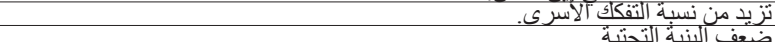 & $1 \varepsilon$ \\
\hline$r, 74$ & $i$ & $\frac{1}{4}$ & or & 120 & 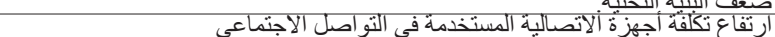 & 17 \\
\hline T,O६ & $\varepsilon$ & 10 & $\varepsilon \Lambda$ & 151 & ضعف شبكات الإنترنت & IV \\
\hline$\frac{r, 7}{r}, 7$ & i & $1:$ & 07 & $\frac{15}{1 \leqslant 2}$ & ضعنف وصبل الإنترنت لعدد كبير من الزراع. & $\frac{11}{19}$ \\
\hline$r, 4 T$ & 1 & $\lambda$ & 00 & $1 \pi \xi$ & 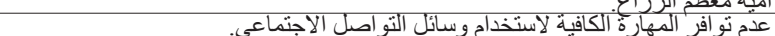 & r. \\
\hline$r, 70$ & $r$ & $\frac{V}{g}$ & $\leqslant 7$ & $1 \leqslant r$ & غياب نظام الدورة الزر أعبة لتوحيد الرسائل الإرشادية من حيّت المحتوي ووقت النشر & 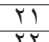 \\
\hline$T, 7 \varepsilon$ & 1 & 9 & 0. & $1 \Gamma \mathrm{A}$ & 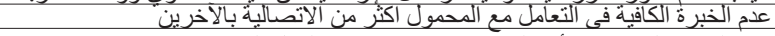 & TY \\
\hline t,Vt & 1 & 7 & ra & 104 & عدم القدرة على قياس الأثر الناتج عن استخدامها فى العمل الزر اعى. & tr \\
\hline$r, 71$ & 1 & 7 & $\varepsilon \lambda$ & IET & امكانبة اختر اق بعض الحسابات. & re \\
\hline T,V: & $\frac{1}{1}$ & $\frac{7}{d}$ & $\frac{\varepsilon r}{0 \xi}$ & $1 \leqslant \lambda$ & 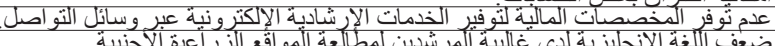 & ro \\
\hline$T, 7 \varepsilon$ & 1 & & $\frac{02}{19}$ & 154 & 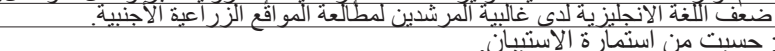 & $\begin{array}{lll}7 \\
د\end{array}$ \\
\hline
\end{tabular}

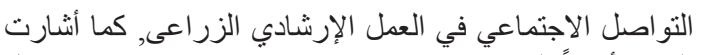

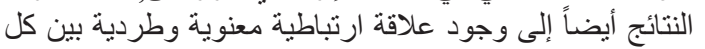

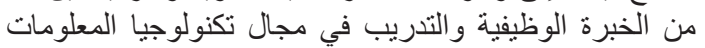

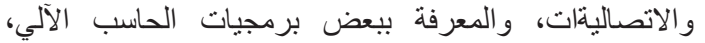

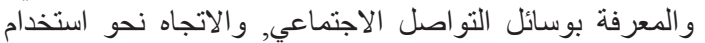

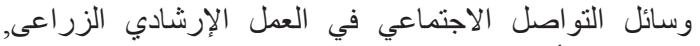

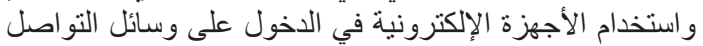

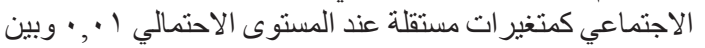

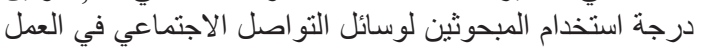

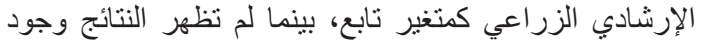

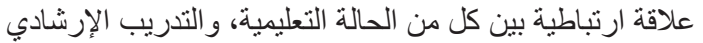

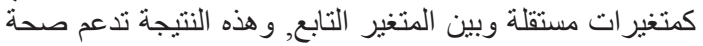

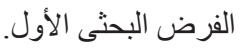

ويتوقع الفرض البحثى الثانى أنه توجد علاقة ارتباطية متعدد

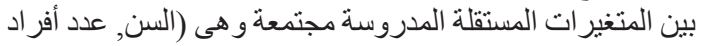

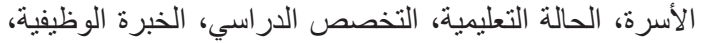

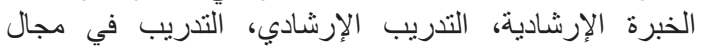

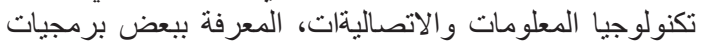

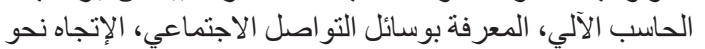

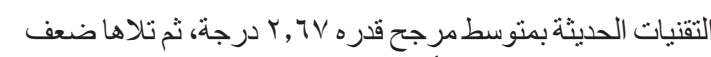

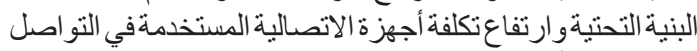

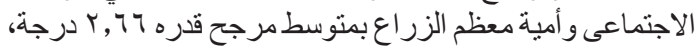

سادساً: العو امل المؤثرة على درجة استخدام المبحوثين لوسائل

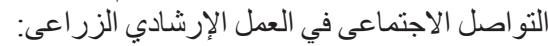

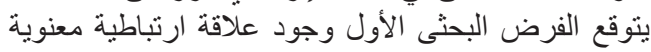

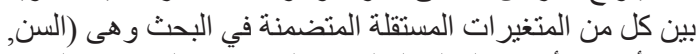

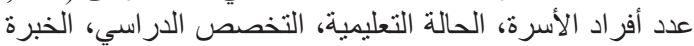

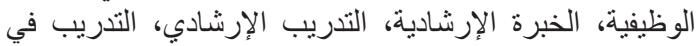

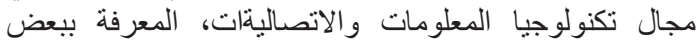

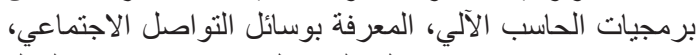

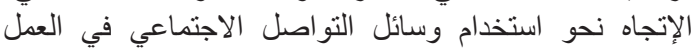

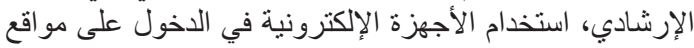

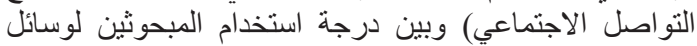
التواصل الاجتماعي في العمل الإرشادي كمتغير تابع.

وقد أظهرت نتائج تحليل الارتباط البسيط بجدول (^) وجود

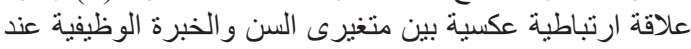

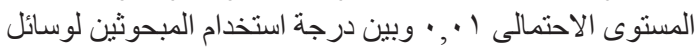

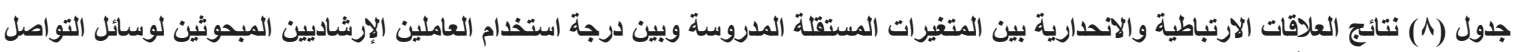

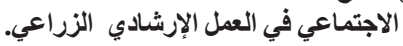

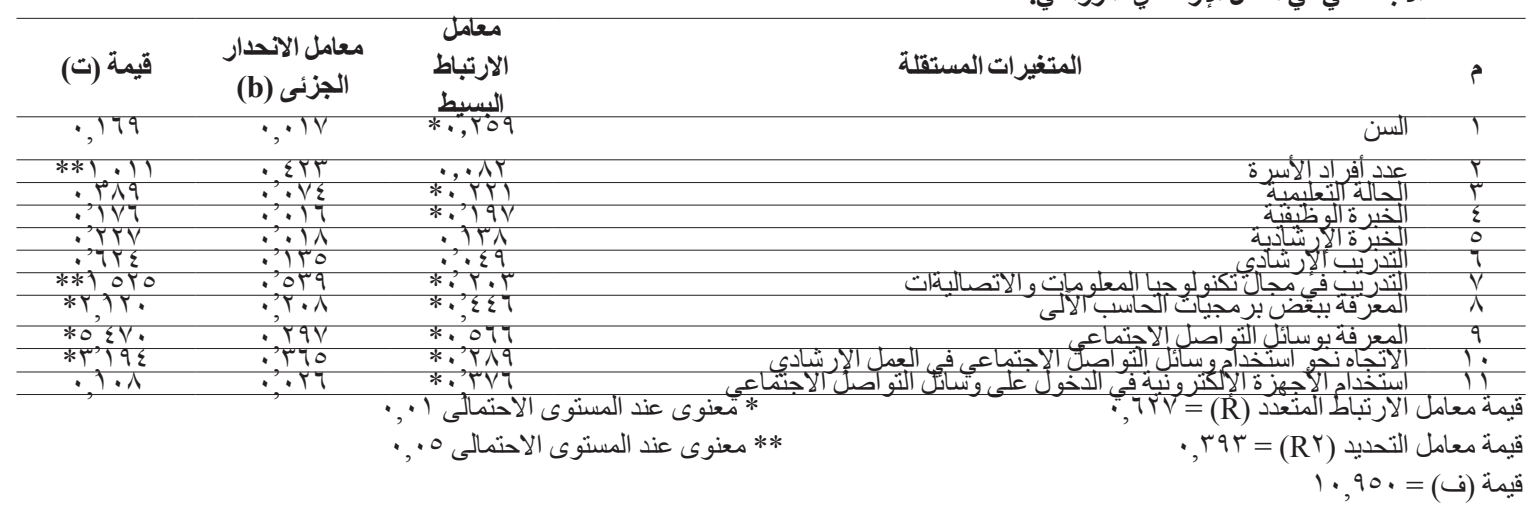

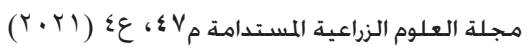


يتوقع الفرض البحثى الثالث أن تسهم المتغيرات المستقلة

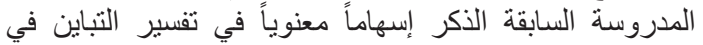

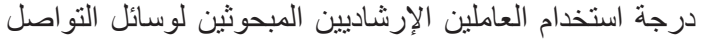

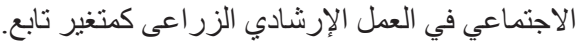

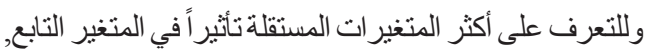

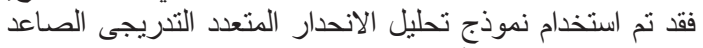

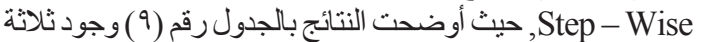

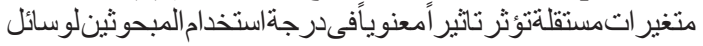

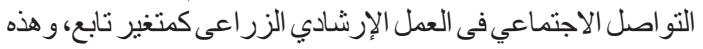

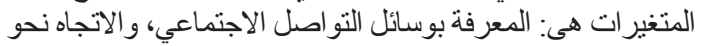

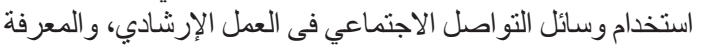

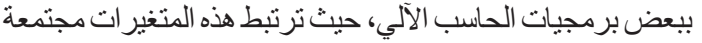

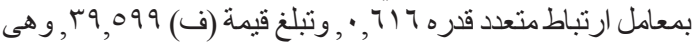

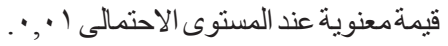

استخدام وسائل التو اصل الاجتماعي في العمل الإرشادي، استخدام

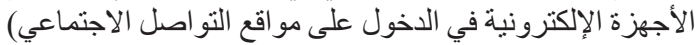

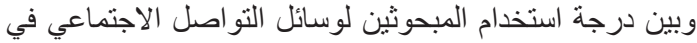
العمل الإرشادي كمتغير تابع.

وباستخدام معادلة الانحدار الخطى المتعدد بين درجة استخدام

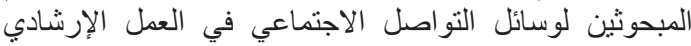

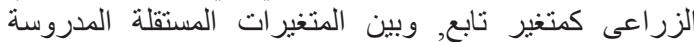

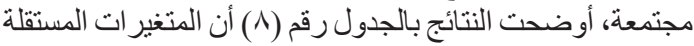

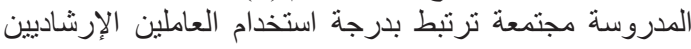

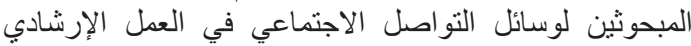

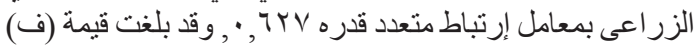

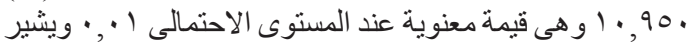

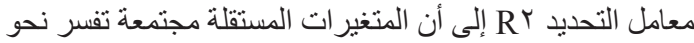

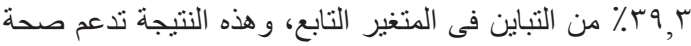
الفرض البحثى الثانى.

جدول (9) نموذج مختزل للعلاقة الارتباطية والاتحدارية المتعددة بين المتغيرات المستقلة وبين درجة استخدام العاملين الإرشاديين المبحوثين لوسائل التواصل الاجتماعي فى العمل الإرشادي الزئل الزراعى كمتغير تابع.

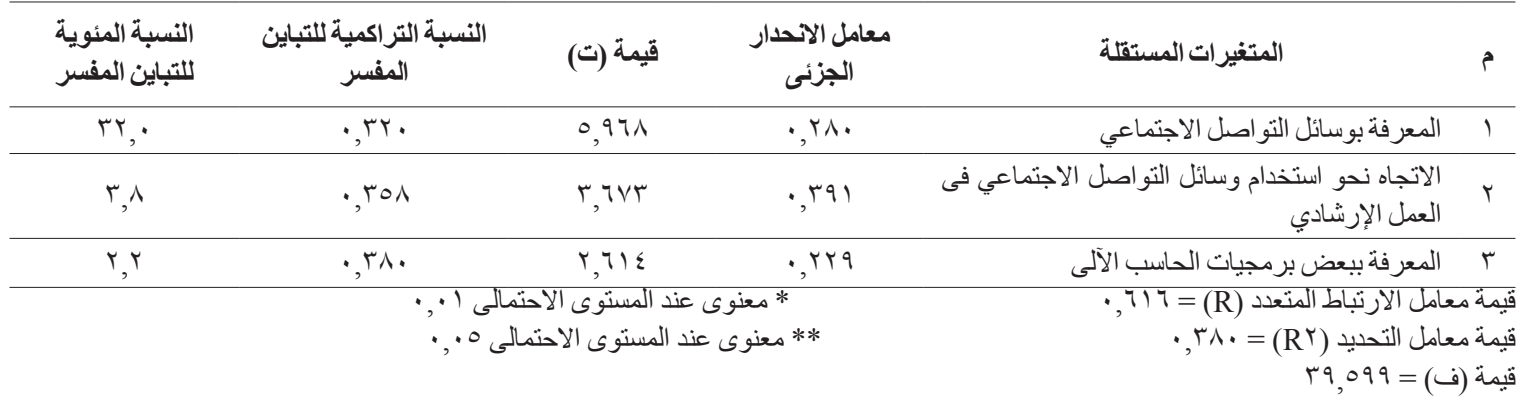

المكتبة الأكاديمية، القاهرة، مصر.

أبو قمر، أميمة رزق مصطفى(Y IV V اتجاهات طلاب كلية

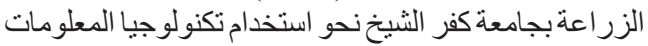

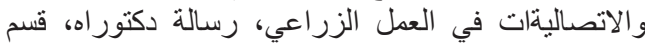
الاقتصاد الزراعي، كلية الزر اعة، جامعة كفر الثيخ.

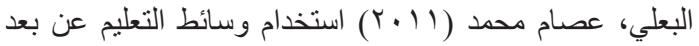

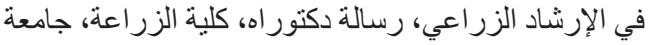

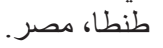

الجبورى، خطاب عبد الله محمد (T 1 ـ ب) ذيوع الافكار الزر اعية

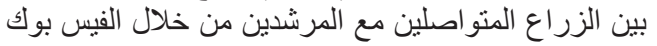

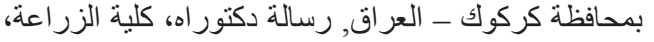

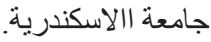

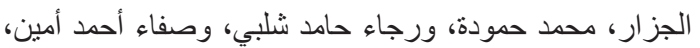

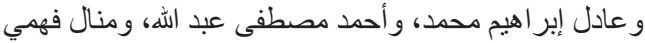

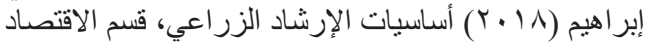
الزر اعي، كلبة الزر اعة، جامعة كفر الثيخ.

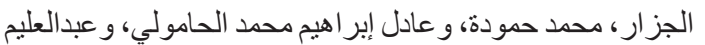

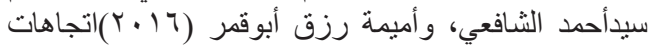

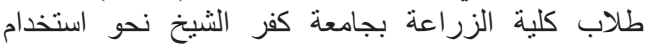
تكنولوجيا المعلومات والاتصاليةات في العمل الزعلية الزراعي

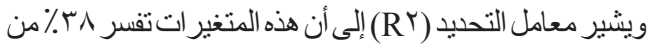

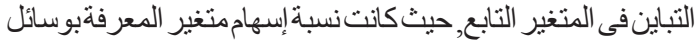

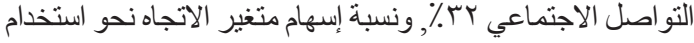

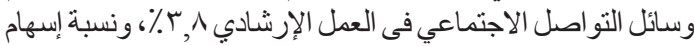

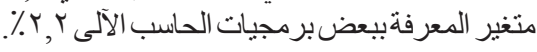

التوصيات

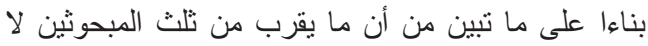

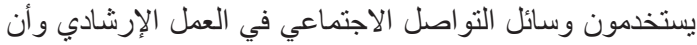

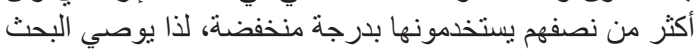

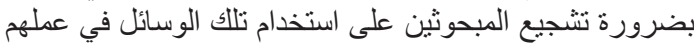

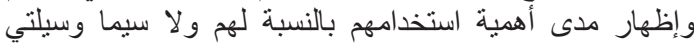

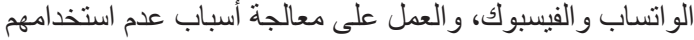
لتللك الوسائل و التغلب على معوقات استخدامها لتحقيق درجة عالية التئ من الرضى عن استخدامها. المراجبــــ

أبو غريب، عايدة عباس، عصام توفيق أبو قمر (997 (19 ) الخدمات

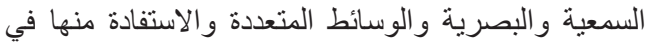

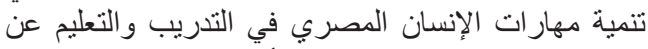

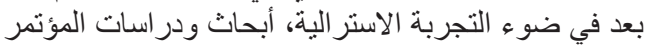

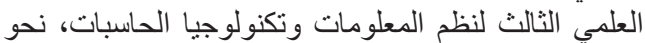
تمهيد الطريق السريع للمعلومات وتحديات التنمية القومية،

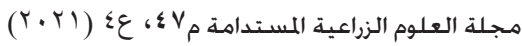


استخدام المرشدين الزراعيين للطرق الإرشادية بالمر اكز

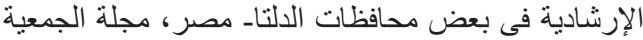

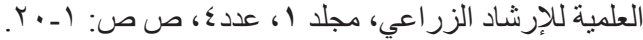

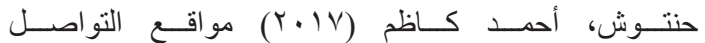

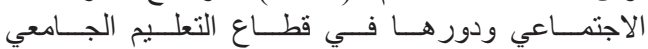

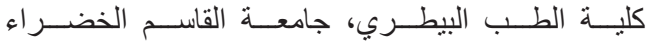

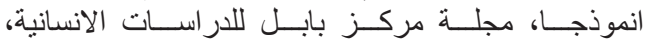

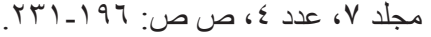

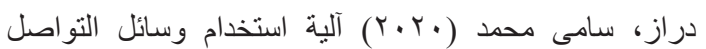

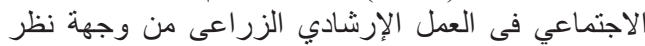

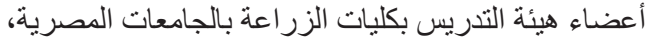

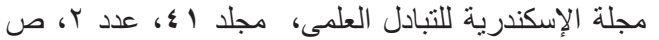

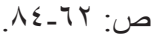

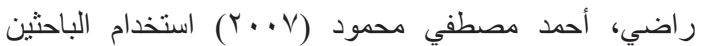

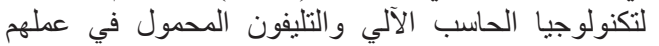

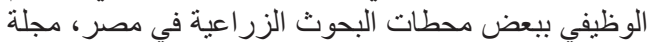

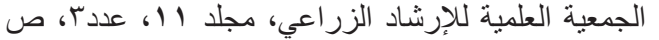

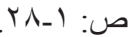

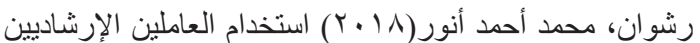

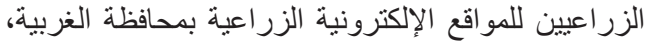

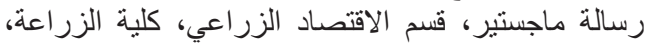
جامعة طنطا.

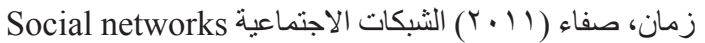
تعريفها وتأثير ها وأنو اعها، جامعة الكويت. الكوية الكويت.

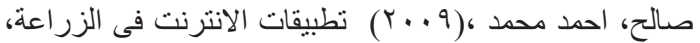

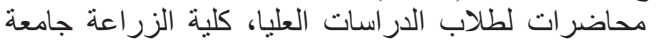
اسيوط.

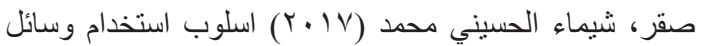

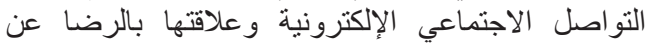

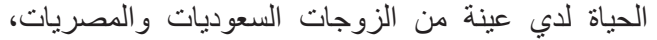

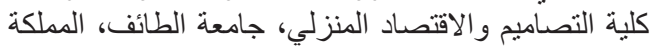

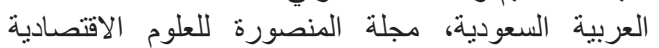

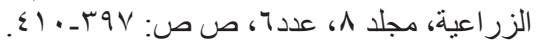

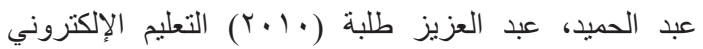

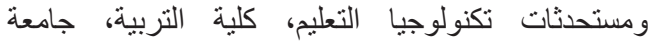
المنصورة، مصرنات

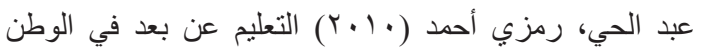
العربي وتحديات القرن الحادي و العشرون، مكتبة العنبة الأنجلو المصرية، القاهرة، مصر. العرن.

عبد الغنى، محمد محمد محمد (9 (1) ب ) در اسة لجاهزية استخدام

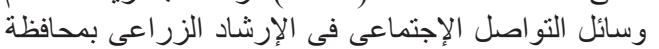

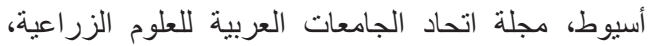

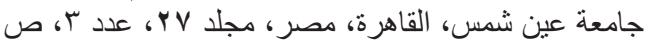
ص:

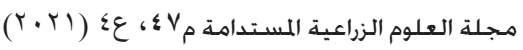

(الهاتف المحمول كمثال)، مجلة البحوث الزر اعية (العلوم

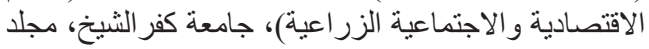
r

الحامولي، عادل إبراهيم محمد (Y) (Y) أثر استخدام الطلاب

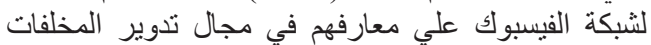

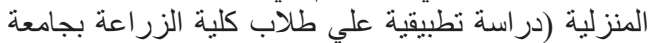

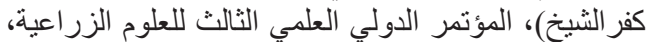

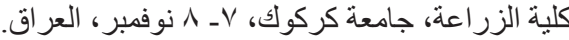

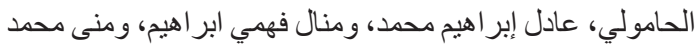

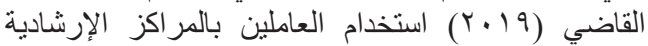

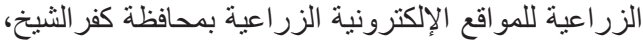

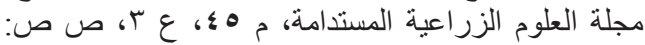
r) $-r^{-1}$

الحامولي، عادل إبر اهيم محمد، وميادة عوض الثو ادفي، و إسر اء

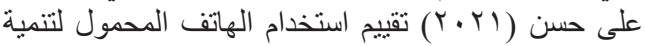

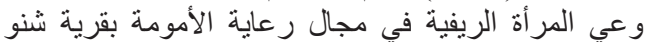

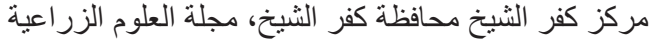

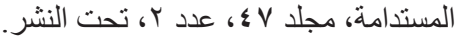

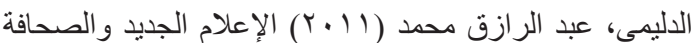
الإلكترونية، دار و ائل للنشر، الطبعة الأولى، الأردن.

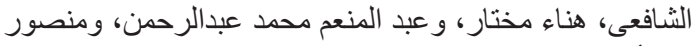

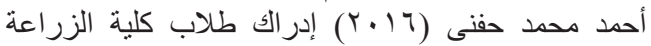

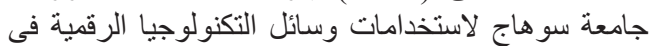

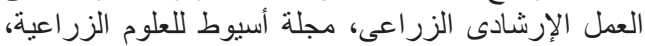

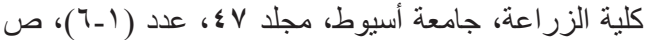

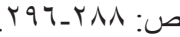

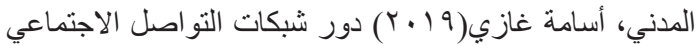

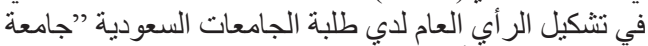

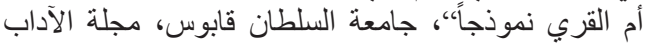

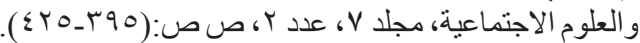

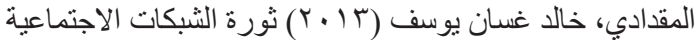

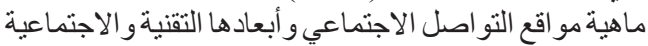

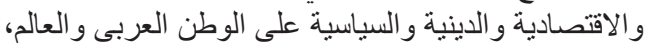
دار النفائس للنشر والتوزيع، عمان، الأردن.

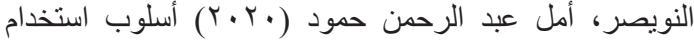

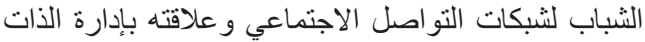

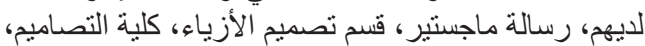
جامعة القصيم، المملكة العربية السعودية.

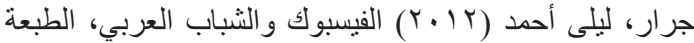
الأولى، مكتبة الفلاح للنشر و التوزيع، الكويت.

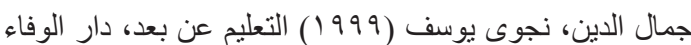

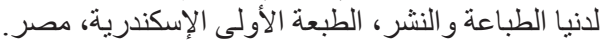
حلمى، أحمد فؤ اد، وحسن شرشر ، وشكرى بدران (ع . . ب) كفاءة 
الدر اسات العلياو البحث العلمى،جامعةالسو دانللعلومو التكنولوجيا.

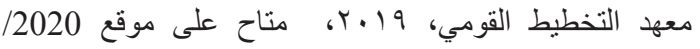
.9/https;//www.inp.edu.eg 20

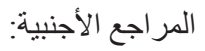

Barau, A., A. and Afrad, S. I. (2017) An overview of social media use in agricultural extension service delivery, .Hungarian Association of Agricultural Informatics European Federation for Information Technology in Agriculture, Food and the Environment, Journal of Agricultural Informatics. Vol. 8, No. 3, pp.: 6150-

Kipkurgat, T., Onyiego, M. and Chemwaina, S. (2016) Impact Of Social Media on Agricultural Extension In Kenya: A Case of Kesses District, International Journal of Agricultural And Rural Development Studies, Vol. 3, No 1, pp. 3036-.

Krejcie, R.V. \& D.W. Morgan (1970)Determining Sample Size for Research Activities, Educational and psychological Measurement, college Station, Urham, North Carolina, USA.

Othman, W., R.,W., Apandi, Z., F., M., and Ngah, N., H. (2016) The uses of Social Media on Student's Communication and Self Concepts among TATIUC Students, Indian Journal of Science and Technology, Vol 9, No., 17, pp.: 18-.

Thakur, D. and Chander, M. (2018a) Use of Social Media in Agricultural Extension: Some Evidences from India, International Journal of Science, Environment, and Technology, Vol. 7, No. 4, pp: 1334- 1346.

Thakur, D. and Chander, M. (2018b): Social Media in Agricultural Extension: Benefits and Challenges under Indian Context, Asian Journal of Agricultural Extension, Economics \& Sociology, 27(2), pp.:81-.

Verduin, JR., Clark,T.A.,Distance Education (1990) The foundation of Effective practice, Jossey Bass Publishers, San Francisco, Oxford.

Bhattacharjee Suchiradipta; Raj Saravanan (2017) Social media: shaping the future of agricultural extension and advisory services, Global Forum for Rural Advisory Services (GFRAS).

Ifejika et al (2019) Available online at: https://www. google.com/search?q=Ifejika+et+al+, 152020/4/.

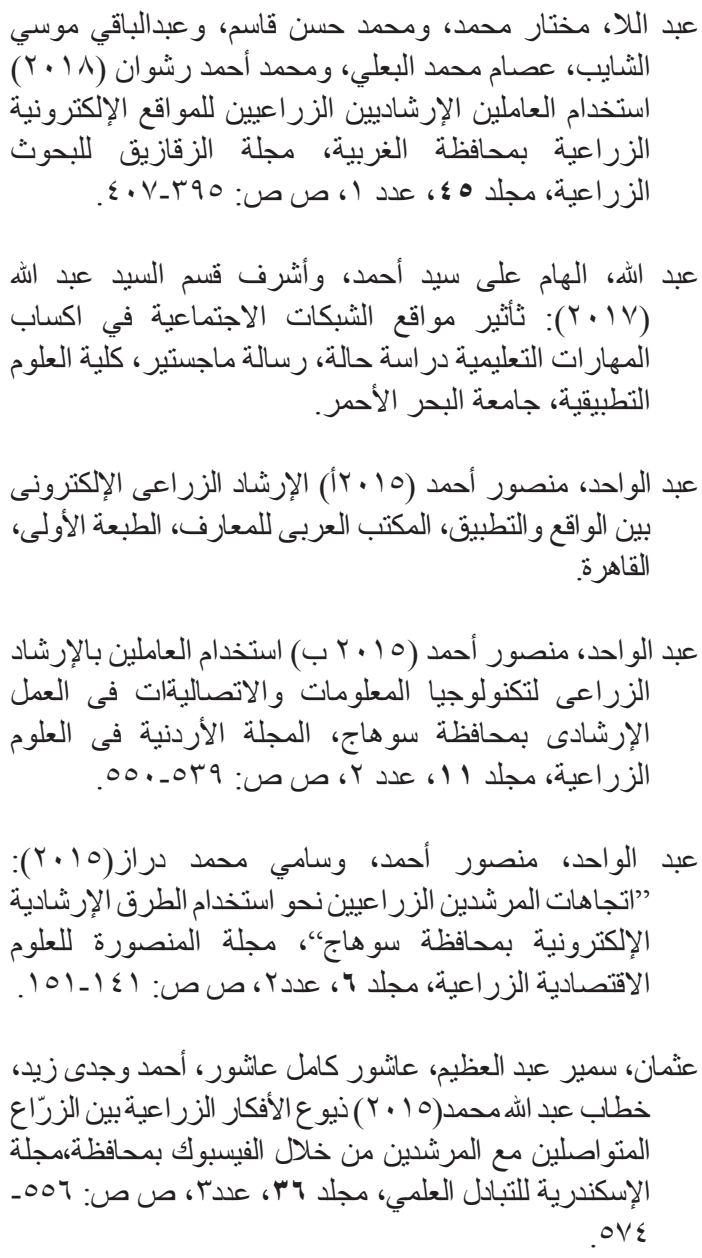

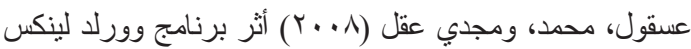

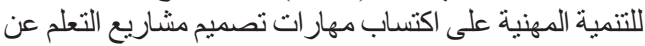

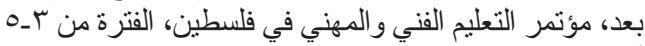
أيلول.

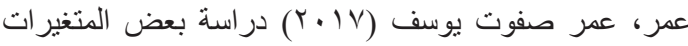

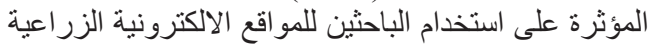

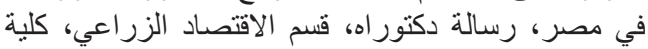

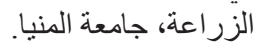

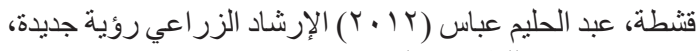
جرين لاين للطباعة، القاهرة.

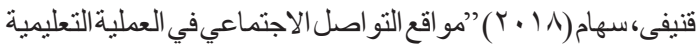

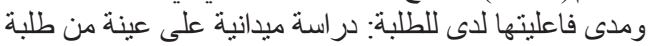

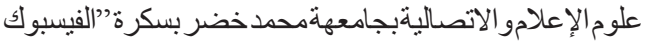

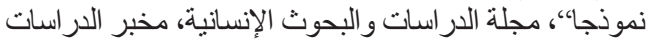

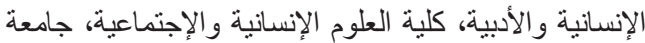

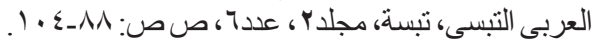

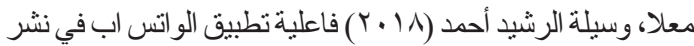

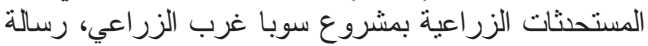
ماجستير غير منشورة، قسم الإرشاد الزر اعى التنتية الريفية الزية، كلية

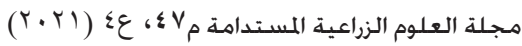




\title{
Use of the Extension Workers Social Media in Extension Work at some Egyptian Governorates
}

\author{
Mohamed H. Elgazzar ${ }^{1}$, Adel I. Elhamoly ${ }^{1}$, Abdelalem S. Elshafay ${ }^{2}$ and Sahar \\ A. Nada $^{2}$ \\ ${ }^{1}$ Agricultural Econmic Dept. Faculty of Agriculture, Kafrelsheikh University \\ ${ }^{2}$ Institute of Agric. Extension and Rural Development, Agric. Researches center
}

$\mathbf{T}$

HIS RESEARCH aims to identify the use of social media by extension workers in the agricultural extension work at some Egyptian governorates. Three governorates were selected: Kafr El-Sheikh, Gharbia, and Beheira, where the extension workers included 463 respondents, the sample size was (210) respondents distributed proportionally over these governorates. The most important results were: $28.8 \%$ of the respondents do not use social media in counseling work, and $69.2 \%$ of them use social media in extension work ranging from low to medium. $33.3 \%$ of them are not satisfied with their use of it in the extension work, and $64.2 \%$ of them range from low to medium satisfaction with their use of it in the extension work. The most important justifications for their use of it were: access to the largest number of beneficiaries in a short time, the possibility of repeating the dissemination of the message more than once to farmers, and the diversity of social media via mobile phones. The most important obstacles included the inability to measure the impact resulting from their use in agricultural work, lack of the financial allocations to provide electronic extension services through the social media. There were three independent variables that have a significant effect on the degree of respondents' use of social media in agricultural extension work: knowledge of social media, trend toward using social media in extension work, and knowledge of using some software computer.

Keywords: Extension, workers, Social media, Facebook, Watsapp, Youtube, Twieter. 